\title{
LA EXTRACCIÓN PREHISPÁNICA DE RECURSOS MINERALES EN EL INTERNODO QUILLAGUA-COSTA, DESIERTO DE ATACAMA
}

\author{
PRE-HISPANIC MINERAL RESOURCE EXTRACTION AT QUILLAGUA-COAST \\ INTERNODE, ATACAMA DESERT.
}

José F. Blanco ${ }^{1}$, Itací Correa G. ${ }^{2}$, Carola Flores ${ }^{3}$ y Gonzalo Pimentel G. ${ }^{4}$

\begin{abstract}
Resumen
En el presente estudio se investigan evidencias de ocupaciones extractivas, desde los resultados de los trabajos arqueológicos en sitios de la conexión vial prehispánica en el internodo entre Quillagua y la costa al norte de Tocopilla en la cordillera de la Costa del desierto de Atacama. Se discuten estos registros en el concierto de lo conocido previamente para la prehistoria de asentamientos y caminera de la costa y el Loa inferior y medio. Se caracteriza una ruta prehispánica y dos segmentos viales, junto con dos sitios extractivos de materiales minerales, una mina y un taller lítico, y se entregan datos de excavación y análisis de ellos, sus materiales culturales, junto con sus fechas absolutas. Usando estos ejemplos, se discute la movilidad de grupos costeros hacia el desierto interior y la de sociedades de Oasis a la Costa, en distintos períodos, tomando en cuenta modelos de movilidad y aprovisionamiento formulados previamente para este espacio. Del mismo modo, tomando en cuenta datos arqueológicos y etnográficos regionales, se proponen hipótesis para la explicación de algunos aspectos de los respectivos casos. Finalmente, se discuten algunos aspectos más generales a la luz de las prospectivas existentes para los Estudios Internodales.
\end{abstract}

Palabras claves: Movilidad - caminos prehistóricos - aprovisionamiento lítico y mineral - desierto de Atacama.

\begin{abstract}
Internodal archaeological evidence of extractive occupations is presented in this study. Evidence comes from the survey and analyses of sites on the prehistoric route between Quillagua (inferior Loa River) and the north Coast of Tocopilla, across the Coastal mountain range of the Atacama Desert. This archaeological record is discussed in relation to previouslyknown prehistoric data about settlements and internodal trails of the Coast, and Inferior and middle Loa sections. We characterize two extractive sites of mineral resources detected in association to pathways, a mine and a lithic workshop. Data from excavations, analyses of archaeological materials and absolute dates are used to discuss mobility of coastal groups to the interior of the desert and of Oasis's societies to the coast in different periods of time. Previously formulated models of mobility and provisioning, as well as regional archaeological and ethnographic data, are used to discuss the presented results, and are applied to examine more general aspects of "Internodal Studies".
\end{abstract}

Keywords: Mobility - prehistoric trails - lithic and mineral provisioning Atacama desert.

\section{* Introducción}

La última década ha visto la emergencia de la denominada "Arqueología Internodal" como un campo de estudios de gran capacidad para aportar a la descripción y discusión de los procesos sociales prehispánicos, especialmente en lo referido a poblaciones de zonas áridas e hiperáridas. En particular, las investigaciones realizadas en el desierto de Atacama, han entregado contextos con gran resolución arqueológica en términos de preservación y de gran relevancia para la interpretación de relaciones prehistóricas entre regiones y localidades, en múltiples escalas geográficas, ampliando así lo que se sabía desde la tradicional arqueología de asentamientos. También, ha provisto de ejemplos claves para la discusión diacrónica de la movilidad e interacción entre ellas. Cabe destacar el rol seminal que cumplieron para la proposición de esta arqueología internodal los trabajos, en décadas anteriores, de Núñez (1976), Núñez y Dillehay (1979), Berenguer (1994 y 2004) y Nielsen (1997), desde distintas perspectivas.

Estos estudios internodales, definidos programáticamente por Berenguer y Pimentel (2010), han generado sistematizaciones teóricas y metodológicas que han sido caracterizadas como heurísticas, en el marco de un proceso de emergencia paradigmático (Núñez y Nielsen 2011). Un enfoque que ha resultado importante en este sentido, ha sido el de Nielsen (2006), formalización a la cual se propone como de índole teórica "histórico-procesual" (sensu Pauketat 2001), destacando su utilidad para la discusión de los procesos sociales asociados a la

Recibido: marzo 2016. Aceptado: noviembre 2016.

1 Arqueólogo. Programa de Doctorado en Arqueología, Universidad Nacional del Centro de la Provincia de Buenos Aires (UNICEN), Olavarría, ARGENTINA. Carampangue 153 piso 3, Valparaíso, CHILE. Email: jfblanco@gmail.com.

2 Arqueóloga. Programa de Doctorado en Arqueología, Facultad de Filosofía y Letras, Universidad de Buenos Aires, ARGENTINA. Email: kusvetiver@gmail.com

3 Doctora en Arqueología. Centro de Ciencia del Clima y la Resiliencia (CR)2, Blanco Encalada 2002, piso 4, Santiago, CHILE. Email: carolaflowers@gmail.com.

4 IAA-San Pedro de Atacama, Universidad Católica del Norte. Fundación Desierto de Atacama, CHILE. Email: gepimentel@ucn.cl 
interacción interregional. ${ }^{5}$ En una explicación reduccionista, esta propuesta cambia el eje de las preguntas que se realizan al registro arqueológico desde un "por qué", tradicional a los estudios de índole adaptativo-ecológico, a la búsqueda de los "cómo" de las prácticas sociales en los procesos históricos sociales prehispánicos. Dicho enfoque ha desarrollado un marco conceptual que, en general, reconoce dos clases generales distintas de sitios relacionados a la movilidad entre nodos poblacionales: las "ocupaciones de tránsito", con gran cantidad de casos discutidos en los Estudios Internodales regionales; ${ }^{6}$ y las "ocupaciones extractivas" (Nielsen 2006:35), menos conocidas.

El trabajo que aquí presentamos, desarrolla una discusión inspirada en una parte de este marco conceptual, la referida a las "ocupaciones extractivas" en ruta, caracterizadas en lo general, como se ha dicho, por Nielsen (2006) con sus respectivos - pero escasos- ejemplos (op. cit., Nielsen et al. 2010). En lo específico, se ha indicado respecto de ellas que: “...podemos plantear una primera clasificación de las mismas en temporarias y transitorias, de acuerdo a su relativa permanencia a corto (duración de cada evento de ocupación) y mediano plazo (recurrencia en la ocupación de los mismos lugares)" (Nielsen 2006: 43).

En referencia a los procesos sociales prehispánicos conocidos en la región, quisiéramos destacar en este estudio que resulta novedosa y relevante la constatación de que no solo las poblaciones de tierra interior tuvieron movilidad a través del desierto, en lo cual había insistido abundantemente la literatura que estudió el "caravaneo", sino que las poblaciones costeras también accedieron a este espacio como agentes diferenciados en busca de materias

\footnotetext{
5 Muy recientemente, Nielsen (2015), ha generado una propuesta de mayor alcance teórico, que supone una síntesis entre la Arqueología Conductual y la Teoría de la Práctica, cuyas derivaciones serán de interés para el desarrollo de los Estudios Internodales, aunque no tratamos sus postulados aquí.

6 En efecto, la mayor parte de los trabajos que pueden considerarse "internodales" en el desierto de Atacama se han sostenido desde el examen de "ocupaciones de tránsito", lo cual tiene su explicación en la enorme relevancia del arte rupestre monumental, geoglifos, abundantísimo en la región (para síntesis generales, ver Briones et al. 2005 y Pimentel 2011). De hecho, el reconocimiento inicial de los sistemas viales prehispánicos en la asociación entre "rutas de caravanas" y arte rupestre, puede considerarse fundacional al respecto (Núñez 1976a, ver también Núñez y Nielsen 2011).
}

primas y de interacción con otros (p.e. Cases et al. 2008, Pimentel et al. 2011, Pimentel 2012), como se había sostenido desde el examen de casos en la costa de Cobija (p.e. Bittmann y Munizaga 1984) y considerando también el área de Taltal y su desierto interior (Núñez 1984), en referencia a la movilidad arcaica.

Para esta época, el Período Arcaico (10.000-3000 AP), el aprovisionamiento lítico en las pampas desérticas ha sido inicialmente estudiado en mayor detalle por ejemplos como los de Urrejola y Orellana (2000), Blanco et al. (2010) y Peralta et al. (2010), existiendo abundantes sitios de extracción con tecnología de núcleos y preformas bifaciales grandes, cuyas etapas de reducción se encontrarían en distintas locaciones entre las fuentes en el desierto profundo y su lugar de uso y descarte en la costa, todo lo cual ha sido refrendado posteriormente por trabajos como los de Galarce y Santander (2013). Sería sobre la base de esta movilidad arcaica que se generó una red vial importante que ha sido verificada a partir de momentos inmediatamente posteriores, en el Período Formativo, por Pimentel et al. (2011).

Entre la costa y el desierto interior de Atacama existieron varias localidades nodales asociadas al río Loa, con población estable a partir del Formativo, que permitieron la interacción entre estos agentes del interior y los costeros y viceversa, notablemente: Quillagua (p.e. Gallardo et al. 1993, Agüero et al. 2006, entre muchos otros); Ancachi (Latcham 1938); Chacance (P. Núñez 2002) y Aldea San Salvador (Torres-Rouff et al. 2012). De éstas, la más im-

\footnotetext{
7 Núñez (1984), sostuvo esto para Taltal con abundante evidencia, pero debe indicarse que el mismo autor, para el caso de la desembocadura del Loa, sugirió inicialmente un proceso de direccionalidad inversa, es decir, de tierras altas a la costa: "Se sugiere que grupos portadores de este patrón habitacional se incorporaron a ciertos enclaves costeros, constituyendo parte de un proceso migratorio entre tierras altas y bajas" (Núñez 1975: 57), dentro de un proceso general de trashumancia, como lo sintetizó Mena (1984), “...reflejo de un momento en que el litoral (aparte de ser explotado regularmente por grupos especializados en la explotación marítima) recibía eventualmente a grupos del interior que establecían ejes terminales en un circuito trashumántico, dedicándose tanto a la caza de auquénidos y mamíferos marinos como a la explotación de recursos típicamente marítimos" (p. 32). Todo ello sigue siendo posible, al no existir evidencia en contra, pero de acuerdo a los trabajos posteriores, debe reconocérsele mayor extensión e injerencia hacia el interior a las poblaciones originalmente costeras, como veremos más adelante.
} 
portante fue Quillagua, con conexiones viales con todos estos lugares, pudiendo entenderse como el nodo principal que articuló las regiones de Tarapacá por el norte (quebradas de Guatacondo y Mani), Atacama por el este (Calama, Alto Loa, Río Salado y, en última instancia, el Salar de Atacama) y toda la costa entre Punta Blanca y la desembocadura del Loa (unos $100 \mathrm{~km}$ de litoral). Este último espacio, presenta abundantes localidades intermedias, puntas y caletas, representadas por una gran cantidad de conchales, sitios habitacionales estructurados y cementerios, todos ellos en general asociados a "aguadas" (p.e. Núñez y Varela 1967-8; Núñez 1972; Llagostera 1990; Salazar et al. 2010 a y b; Gallardo et al. $2015 \mathrm{~ms}$ ), espacios poco estudiados en la literatura arqueológica. En fin, existe una miríada de caminos, que recorren esta sección del desierto de Atacama, aún reconocibles pese a la explotación minera de tiempos modernos y a la destructiva actividad de "competiciones" vehiculares como el nefasto rally Dakar. ${ }^{8}$ Se han trabajado arqueológicamente varias de estas rutas en distintas ocasiones (p.e. Cases et al. 2008; Pimentel et al. 2011; Pimentel 2012; Blanco 2013).

El presente caso de estudio corresponde a la ruta prehispánica en el internodo entre Tocopilla y Quillagua, nodos distantes unos $90 \mathrm{~km}$ entre sí y mediados por una de las secciones más áridas del desierto de Atacama y del planeta (Ortlieb 1995). El estudio de esta ruta busca realizar una discusión con nuevos datos y desde una perspectiva "diacrítica" (sensu Berenguer 2004: 23), que permita comparar agentes de ambas regiones, Costa y Oasis interiores, ${ }^{9}$ y acceder al análisis de un modelo de movilidad formulado previamente para este espacio por Pimentel et al. (2011), basado en el estudio de "ocupaciones de tránsito". Este modelo, planteado para el Período Formativo, pone en clave comparativa agentes costeros y de oasis, y propone las siguientes características para su

8 De hecho, los autores constatan aquí que parte de la ruta estudiada en este trabajo, ha sido destruida por una de las versiones de este evento.

9 Resulta asombroso que a lo largo de la literatura de los Estudios Internodales en el área andina centro-sur, prácticamente no se reconozca a la costa como una "región nodal". Advertimos al lector de que, en este caso, nosotros operaremos desde esta presunción, que deberá discutirse más ampliamente en otra ocasión, pero que considerando su geografía humana, recursos y topografía, y que posee poblaciones con adaptación propia e independiente, no debería ser difícil de establecer. ocupación internodal: 1) Para la movilidad costera: un objetivo de aprovisionamiento logístico, con mínima inversión en infraestructura, baja escala de contingentes (idos a tres individuos?), alcance espacial restringido (unos 70 $\mathrm{km}$ ) y baja intensidad de tránsito; vías de sendero único; estructuras de alojamiento aisladas; mayor evidencia de talla lítica, reducción de núcleos y preparación de matrices bifaciales de carácter local; escasa presencia cerámica (tipos cerámicos tempranos LCA, LMS-B1); alta diversidad interzonal con mayor énfasis en productos costeros; sin geoglifos ni restos de fecas de camélido o mineral de cobre; y, 2) Para la movilidad caravanera: un objetivo de intercambio intersocietal, con cierta inversión en infraestructura y escala de contingentes mayor (ide tres a nueve individuos?), movilidad ampliada a más de $100 \mathrm{~km}$ y alta intensidad y redundancia; senderos múltiples y sinuosos; menor evidencia de talla lítica sobre núcleos de obtención oportunística y reavivado de herramientas en rocas alóctonas; mayor evidencia cerámica y contenedores de calabaza; mayor equilibrio interzonal en sus productos; presencia de geoglifos, fecas de camélido y mineral de cobre triturado (Pimentel et al. 2011: 68).

En este sentido, el estudio que aquí presentamos fue planteado para proveer mayor profundidad analítica a distintos aspectos de ambos modelos (p.e. Nielsen 2006, Pimentel et al. 2011), especialmente al tema de los líticos y minerales, considerando en detalle las "ocupaciones extractivas", en tanto el modelo más específico a nuestra área de estudio (Pimentel et al. 2011) tiene como base exclusiva el estudio de "ocupaciones de tránsito", considerando estas materialidades desde una perspectiva más amplia. Hemos incluido también, en la sección de discusión, un examen de las ocupaciones extractivas detectadas, tomando como referencia una sección del modelo de Salazar y Salinas (2008), referida a la tecnología y los procesos técnicos de la minería regional. Del mismo modo, revisamos datos arqueológicos y etnográficos que pudieran entregar hipótesis explicativas de la naturaleza del consumo de los productos de uno de los casos. Destacamos, por último, que en el presente trabajo se caracteriza inicialmente una conexión vial prehispánica previamente no estudiada en la literatura, entre el Loa medio y la costa. 


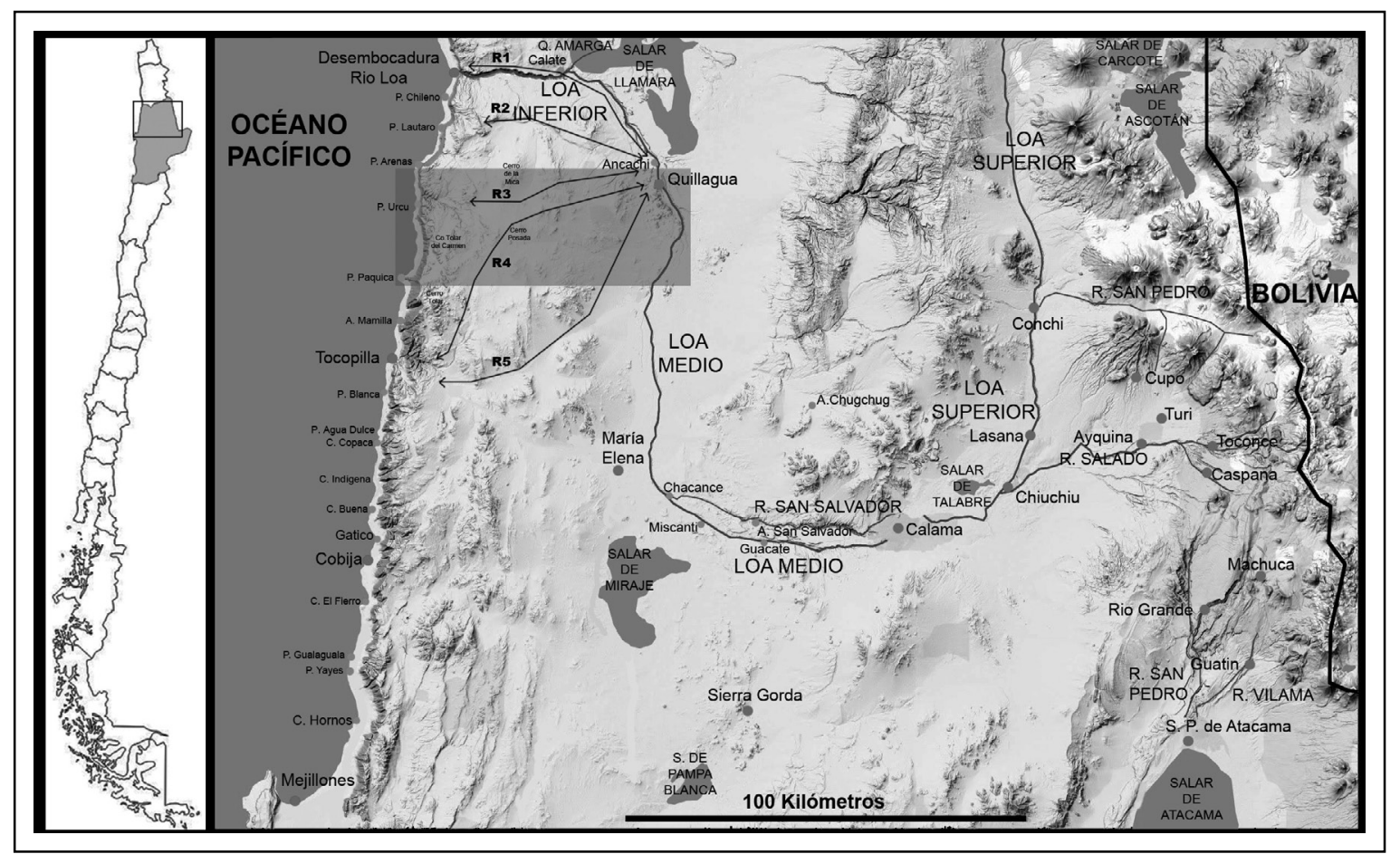

Figura 1. Esquema general del área de estudio en su contexto regional. Las flechas en negro indican el trazado aproximado de las rutas que se mencionan. El rectángulo sombreado indica el área de estudio específica, superficie que corresponde al detalle que presentamos en la Figura 2, más adelante en la sección de resultados. El norte está arriba.

\section{La ruta Tocopilla-Quillagua (TQ) y las vías de movilidad estudiadas}

La conexión entre Quillagua y la costa presenta varias rutas o conexiones, conformadas a veces por varias vías, entre las cuales las principales son, de norte a sur: 1) a la desembocadura del Loa, pasando por Ancachi, los cerros de Calate y Quebradillas al norte del Loa; 2) a las puntas Chileno y Lautaro, directo por el norte del cerro de la Mica y al sur del Loa; 3) a caleta Urcu, desde el norte de Quillagua (Ancachi), pasando por el sur del cerro de la Mica; 4) a Tocopilla y su costa norte, con varios desvíos y variantes (que aquí se presentan y discuten); y, 5) a Tocopilla y Punta Blanca por la Pampa el Toco y el paso Galenosa. En el mapa general (Figura 1) se muestran esquemáticamente las rutas indicadas.

En principio, hemos denominado esta ruta y vía como Tocopilla-Quillagua (TQ), con la costa por delante, solo por destacar este componente social, escasamente investigado en su dimensión vial en comparación con las redes de oasis y tierras altas. No obstante ello, iniciaremos su descripción desde Quillagua, por tratarse de una locali- dad arqueológica más conocida, y porque, desde la costa, en el extremo oeste, la red vial presenta caminos desde diversos lugares en $c a .45 \mathrm{~km}$ lineales de litoral, entre Tocopilla y Caleta Urcu, razón por la cual podemos considerar este extremo como un nodo disperso. ${ }^{10}$ Estos distintos caminos convergen en el extremo este de la ruta, presentando esta vía un trazado único en sus últimos 15 $\mathrm{km}$ antes de llegar al oasis.

Nuestra vía TQ es atravesada por otras que provienen de distintos lugares en el desierto interior, notablemente desde el Loa medio, la vía señalada por Pimentel et al. (2011) como vía A2107, descrita en la Pampa El Toco, que contiene un entierro del Período Formativo Medio (op. cit., Cases et al. 2008; Knudson et al. 2010), que ha servido como caso emblemático para sostener la agencia costera en caminos al interior del desierto. Esta ruta se originaría en el Loa medio, con destino a Punta Paquica y

10 Esta distinción no ha sido realizada en la literatura, hasta donde sabemos, y sus esencialidades y derivaciones analíticas deberían ser examinadas en más detalle. De todas formas la aceptaremos provisoriamente. 
Aguada de Mamilla, aunque tiene correlato hacia el este, en una vía que conduce a la Aguada de Chug-Chug ( $\mathrm{Pi}$ mentel 2012) y, por lo tanto, puede suponerse también que hacia Calama, primer oasis de las "cuencas intramontanas", más o menos en el límite entre el Loa medio y superior (sensu Berenguer 2004).

El trazado que tomamos como central de la Ruta TQ, es una vía de huella múltiple que conecta Quillagua y Tocopilla, por el camino de la Antena, Cerro Posadas y Quebrada Tres Amigos en un rumbo general de $235^{\circ}$ SSW. Su largo total es de $90,5 \mathrm{~km}$, considerando que no se ha detectado su parte terminal y se ha estimado por menor resistencia, es decir, por el interior de la quebrada cuyo piso presenta rellenos aluvionales recientes, a partir de los $73 \mathrm{~km}$ por la quebrada mencionada, pleno descenso a la costa atravesando las estribaciones oeste de su cordillera. La vía TQ atraviesa cuatro secciones geográficas distintas: a) Pampa de Depresión Intermedia (10 km, 900-1000 msnm); b) Estribaciones este de la cordillera de la Costa ( $5 \mathrm{~km}, 1000-1400 \mathrm{msnm})$; c) Meseta alta ( 58 km, 1400-1550 msnm, con máxima en 1740 msnm en el $\mathrm{km}$ 45, parte norte del cerro Posada); y, d) Estribaciones oeste de la cordillera, incluyendo el farellón costero (17,5 $\mathrm{km}, 1550-\mathrm{o} \mathrm{msnm}$ ).

La vía posee distintos desvíos y variantes, los primeros se encuentran todos al norte y los segundos, al sur. Los desvíos conducen, aparentemente $\mathrm{a}$ : $\mathrm{dl}$ ) Desde el $\mathrm{km} 15$ de TQ, a la costa entre Punta Arenas y caleta Urcu, vía sur del cerro de la Mica y por quebrada Iquine; d2) Desde el km 24, a Punta Arenas o al norte de ésta (puntas Lautaro y Chileno), vía cerro de la Mica; $\mathrm{d}_{3}$ ) Desde el km 30, a caletas Urcu y Huamán, por el sur del cerro de la Mica y al norte del cerro Tolar del Carmen; d4) Desde el $\mathrm{km}$ 43, al espacio entre caleta Urcu y Punta Paquica, por el norte del cerro Del Rumbo y entre las estribaciones sur-este del cerro Tolar del Carmen, que corresponde a un segmento aquí estudiado. Por su parte, las variantes, es decir, las alternativas que se desprenden de la vía y que retornan a ella posteriormente, son dos, aunque corresponden a una sola vía con dos accesos distintos, en el $\mathrm{Km} \mathrm{13,5} \mathrm{y} \mathrm{después} \mathrm{en} \mathrm{el} \mathrm{Km} \mathrm{20}$, volviendo a su trazado central en el $\mathrm{Km} 48$. Esta alternativa discurre paralela al sur de TQ a una distancia máxima de $6 \mathrm{~km}$. El largo máximo de esta variante es de $50 \mathrm{~km}$, dos más larga que la ruta central. La diferencia entre ambas está dada por la presencia del cerro Posada, que la vía TQ salva por el norte y su variante, con sus dos accesos, por el sur (Figura 2).

\section{* Metodología}

En atención a la idea general de agentes distintos circulando por el mismo internodo, seleccionamos para nuestro trabajo dos tramos de vía dentro de la ruta, que fueran morfológicamente distintos. Tomando en cuenta que se ha propuesto que las huellas simples corresponderían a la agencia costera sin animales de carga, y las múltiples a poblaciones con este manejo zootécnico, comenzamos nuestra prospección por una de las variantes de la vía, que asumimos como representativa de la movilidad costera, por tratarse de una huella simple, un tramo de $16,5 \mathrm{~km}$ que corresponde al desvío cuatro ( $\left.\mathrm{d}_{4}\right)$ mencionado previamente. La segunda sección corresponde a los $43 \mathrm{~km}$ restantes hasta Quillagua, y consiste en una huella múltiple con anchos variables de hasta $30 \mathrm{~m}$. Se prospectó de manera pedestre siguiendo la vía de oeste a este, y registrando los sitios en cuaderno de campo, con sus respectivas fotografías digitales y registro GPS. La prospección empleó dos transectas paralelas a la huella, una por cada lado de la vía, registrándose los hallazgos relacionados a ella a nivel de sitio, considerando una distancia de $200 \mathrm{~m}$ desde su eje. Se emplearon fichas estandarizadas provistas por el proyecto FONDECYT 1090762. El trabajo de prospección se diseñó y realizó de modo tal que simulara el viaje prehispánico pedestre entre la cordillera de la Costa y Quillagua, cargando las personas que prospectaron su propia agua y comida. Usando este método, sin apoyo de vehículos motorizados, se cubrió una distancia exacta de $76 \mathrm{~km}$, en un lapso de cuatro días y tres noches.

Una vez detectadas las "ocupaciones extractivas" asociadas a la vía, que resultaron ser dos, procedimos a realizar un registro de sus atributos empleando una ficha ad hoc para cada una, un levantamiento topográfico, dibujo técnico, recolección superficial y excavación de sondeo. Por último, realizamos análisis arqueológicos para cada materialidad; fechados radiocarbónicos por AMS para cada capa y físico-químicos, para los materiales explotados.

Respecto de la lítica, se apuntó a una clasificación morfológica de los productos descartados, realizada sobre 
los componentes principales de variación a observar, en una base de datos del material. Se emplearon las variables descriptivas y procedimientos metodológicos definidos para los análisis líticos del proyecto FONDECYT 1090762 (Blanco 2013), con el propósito de mantener comparabilidad analítica intrarregional con los materiales previamente recuperados por este mismo proyecto. Sus bases descriptivas y metodológicas pueden hallarse en Aschero (1975 Ms), Bate (1971), Andrefsky (2000) y Odell (2003).

Para el caso de la cerámica, se examinó la fragmentería en función de los criterios metodológicos de Shepard (1985 [1956]) y Rice (1987), llevando a cabo también una adscripción tipológica basada en los trabajos de Varela (1992, 2002) y de Uribe y colaboradores (Uribe y Ayala 2004; Uribe 2004; Uribe et al. 2007), con el fin de lograr una aproximación a la cronología y proveniencia del material. Esta tarea también se basó en la comparación del material con muestrarios disponibles generados a partir de las colecciones del proyecto y la aplicación de una metodología más específica de análisis para cerámica en contextos de ruta, que calibra la representatividad de los tipos cerámicos en función del mínimo número de vasijas (Correa y García 2014).

Los materiales malacológicos fueron identificados a nivel de especie utilizando claves y catálogos para la costa de Chile (p.e. Marincovich 1973; Guzmán et al. 1998), y cuantificados siguiendo consideraciones metodológicas presentes en Glassow (2000), Claassen (2000), Massons et al. (1998 y 2000) y Lucero (2004). El resto de las materialidades recuperadas, vegetales (madera, ramitas y fragmentos) y fanéreos, fue analizado a nivel descriptivo solamente. Para conocer las características químicas de los materiales líticos y minerales extraídos, muestras de éstos fueron enviadas a laboratorios especializados para su análisis por observación microscópica, espectroscopia RAMAN y pXRF.

Aunque se relevaron abundantes detalles en cada análisis de las diferentes materialidades, en atención a la escala de trabajo de este artículo, trabajaremos aquí solamente con los resultados más generales.

\section{$*$ Resultados}

Los sitios identificados en la prospección se sistematizan en la Tabla 1 según denominación, coordenadas, ${ }^{11}$ altitud, tipo de sitio, tamaño, tipo de vía asociada y una breve descripción de sus contenidos. Más adelante, desarrollamos los datos obtenidos de las intervenciones específicas de los casos que correspondieron a "ocupaciones extractivas" de líticos y minerales.

Se detectaron 24 sitios arqueológicos asociados a los dos segmentos viales prospectados, principalmente 10 sitios de arte rupestre (geoglifos), la mayor parte de los cuales habían sido mencionados por Pimentel (2011) y Briones y Castellón (2013). Otras categorías se encuentran representadas por sitios de pernocte (paskanas en depresión y estructuras $n=10$ ), al menos dos estructuras funerarias y dos sitios de carácter extractivo, que son los que aquí presentamos in extenso (cf. Blanco 2013). La distribución de estos registros puede consultarse en la Figura 2.

\section{TQO1 mina arcaica costera}

Este sitio se encuentra ubicado en la parte alta de la cordillera de la Costa (1612 msnm). La distancia lineal entre la mina y la línea de costa es de $11 \mathrm{~km}$, aunque medida por sobre la huella pedestre alcanza los $13 \mathrm{~km}$ hasta caleta Huamán, uno de los puntos conectados por ella, $15 \mathrm{~km}$ a punta Paquica y $19 \mathrm{~km}$ hasta caleta Urcu. Existe entre la mina y cualquier punto de la costa un farellón rocoso de 700 a $1000 \mathrm{~m}$ de altura, con escarpes de hasta $1300 \mathrm{~m}$ que se desarrollan en apenas $2 \mathrm{~km}$ horizontales (Figura 2).

TQO1 posee aproximadamente 18 ha de superficie, donde se detectaron 158 extracciones de yeso o anhidrita. ${ }^{12}$ Las extracciones presentan, por todo el perímetro, un desecho de extracción ("ganga"), consistente en pequeñas piedrecillas angulares lustrosas. En algunas extracciones se detectó un relleno microaluvial que podría corresponder, al parecer, a una única lluvia en la historia del sitio, considerando la nula erosión de perfiles expuestos en ellos.

11 Unidades Transversales de Mercator (UTM), World Grid System 84 (WGS84), Huso $19 \mathrm{~K}$.

12 Como se verá más adelante, los métodos de análisis químico identificaron preponderancia de $\mathrm{CaSO}_{4}$, anhidrita, que en su forma hidratada se conoce como yeso $\left(\mathrm{CaSO}_{4}-2 \mathrm{H}_{2} \mathrm{O}\right)$. En adelante usaremos la expresión "yeso". 


\begin{tabular}{|c|c|c|c|c|c|c|c|c|}
\hline Sitio & UTM E & UTM N & 总 & $\begin{array}{l}\text { Tipo de } \\
\text { sitio }\end{array}$ & $\begin{array}{l}\text { Eje mayor } \\
\text { sitio }(\mathrm{m})\end{array}$ & $\begin{array}{l}\text { Eje menor } \\
\text { sitio }(\mathrm{m})\end{array}$ & Tipo Vía & Descripción General \\
\hline TQO1 & 361672 & 7582566 & 1570 & Mina & 700 & 400 & Simple & $\begin{array}{l}\text { Extracciones en pequeños piques ovales y algunos alargados, } \\
\text { dispuestas en su mayoría en laderas de cerro, al norte y al sur del } \\
\text { sitio, a lo largo de un manto de sedimentos blancos. }\end{array}$ \\
\hline TQO2 & 414063 & 7589167 & 1673 & $\begin{array}{l}\text { Cantera- } \\
\text { Taller }\end{array}$ & 150 & 150 & Múltiple & $\begin{array}{l}\text { Oquedades artificiales, subovales al costado } \mathrm{S} \text { de la huella y bajo } \\
\text { ella. Restos de talla en placas de roca dispersa como regolito. } \\
\text { Geoglifos: varias figuras geométricas ( } 6 \text { ). Rombo escalerado de } \\
\text { cuatro pisos compuesto por } 10 \text { rectángulos y } 2 \text { trapecios. }\end{array}$ \\
\hline TQO3 & 435153 & 7599524 & 1262 & Geoglifos & 17 & 7 & Múltiple & Representación de 2 camélidos en fila. \\
\hline TQO4 & 434805 & 7599451 & 1264 & Geoglifos & 24 & 3 & Múltiple & $\begin{array}{l}\text { Serpiente compuesta por línea zigzagueante. En parte superior de la } \\
\text { cabeza presenta boca y ojo de perfil. Hay otros dos motivos. }\end{array}$ \\
\hline TQO5 & 431373 & 7599628 & 1391 & Geoglifos & 100 & 30 & No tiene & Siete figuras. 2 aves tipo condor. 1 cayado. Tortuga o anfibio. \\
\hline TQ06 & 431708 & 7598564 & 1421 & Geoglifos & 50 & 50 & Simple & $\begin{array}{l}\text { Al menos } 12 \text { figuras geométricas y figurativas. Ballena o lobo } \\
\text { marino dispuesto en diagonal. }\end{array}$ \\
\hline TQO7 & 427239 & 7596662 & 1497 & Geoglifos & 500 & 100 & Múltiple & $\begin{array}{l}\text { Múltiples figuras en varios paneles }(n=73) \text {. Destacan grandes } \\
\text { "insectos", una diadema que corona el cerro y un panel con una } \\
\text { secuencia vertical de entunicados. También hay un balsero. }\end{array}$ \\
\hline TQ०8 & 423481 & 7595004 & 1517 & Paskana & 40 & 20 & Múltiple & $\begin{array}{l}\text { Dos estructuras circulares de doble hilada al } \mathrm{N} \text { de la huella, vanos } \\
\text { abiertos hacia el SE, con mortero. }\end{array}$ \\
\hline TQ०9 & 423638 & 7595010 & 1511 & Estructura & 15 & 15 & Múltiple & Amontonamiento irregular de piedras. \\
\hline TQ10 & 421985 & 7595187 & 1597 & Geoglifos & 20 & 20 & Múltiple & Estructura circular u ovoidal de $4 \mathrm{~m}$ de diámetro. \\
\hline TQ11 & 420894 & 7593695 & 1551 & Estructura & & & Múltiple & Amontonamiento irregular de piedras. \\
\hline $\mathrm{TQ}_{12}$ & 419776 & 7593185 & 1546 & Estructura & & & Múltiple & Amontonamiento irregular de piedras. \\
\hline TQ13 & 418149 & 7592480 & 1560 & Tumbas & 400 & 300 & Múltiple & $\begin{array}{l}\text { Amontonamientos de clastos en los lados norte y sur de huella. Uno } \\
\text { de ellos corresponde a tumba. }\end{array}$ \\
\hline TQ14 & 417364 & 7592084 & 1595 & Estructura & & & Múltiple & Amontonamiento irregular de piedras. \\
\hline $\mathrm{TQ} 15$ & 413084 & 7588206 & 1560 & Paskana & 50 & 50 & Múltiple & $\begin{array}{l}\text { Paskanas con piedras, algunas circulares, a ambos lados de la huella. } \\
\text { Hay dos "cajitas". }\end{array}$ \\
\hline TQ16 & 412854 & 7588083 & 1648 & Geoglifos & 100 & 30 & Múltiple & Dos figuras. Taruca (?). Rombo escalerado. \\
\hline TQ17 & 412214 & 7587873 & 1659 & Geoglifos & 30 & 30 & Múltiple & Seis figuras. Fitomorfos (maiz?), rombos escalerados y diadema. \\
\hline TQ18 & 413533 & 7587717 & 1625 & Estructura & 2 & 2 & Múltiple & Amontonamiento de lajas al $700 \mathrm{~m}$ al SSW de huella. \\
\hline TQ19 & 424958 & 7595715 & 1503 & Tumba? & 50 & 20 & Múltiple & $\begin{array}{l}\text { Depresión rodeada por piedras de pequeño tamaño. Hay una } \\
\text { posible tumba saqueada. }\end{array}$ \\
\hline $\mathrm{TQ}_{20}$ & 422238 & 7594342 & 1533 & Estructura & 10 & 10 & Múltiple & Amontonamiento irregular de piedras. \\
\hline $\mathrm{TQ}_{21}$ & 418697 & 7592698 & 1559 & Estructura & 10 & 10 & Múltiple & Amontonamiento irregular de piedras. \\
\hline $\mathrm{TQ} 22$ & 421103 & 7594000 & 1566 & Geoglifos & 30 & 20 & Múltiple & Tres figuras: Felino, ofidio y líneas radiadas. \\
\hline $\mathrm{TQ}_{23}$ & 426650 & 7596589 & 1483 & Estructura & 50 & 20 & Simple & $\begin{array}{l}\text { Dos grandes señalizadores de ruta, flanqueando la huella simple } \\
\text { que se desvía al suroeste. }\end{array}$ \\
\hline TQ24 & 432224 & 7598827 & 1398 & Geoglifos & 40 & 20 & Simple & $\begin{array}{l}\text { Siete figuras: varios lobos marinos o ballenas. Círculos y } \\
\text { rectángulos. }\end{array}$ \\
\hline
\end{tabular}

Tabla 1. Resultados de la prospección. 


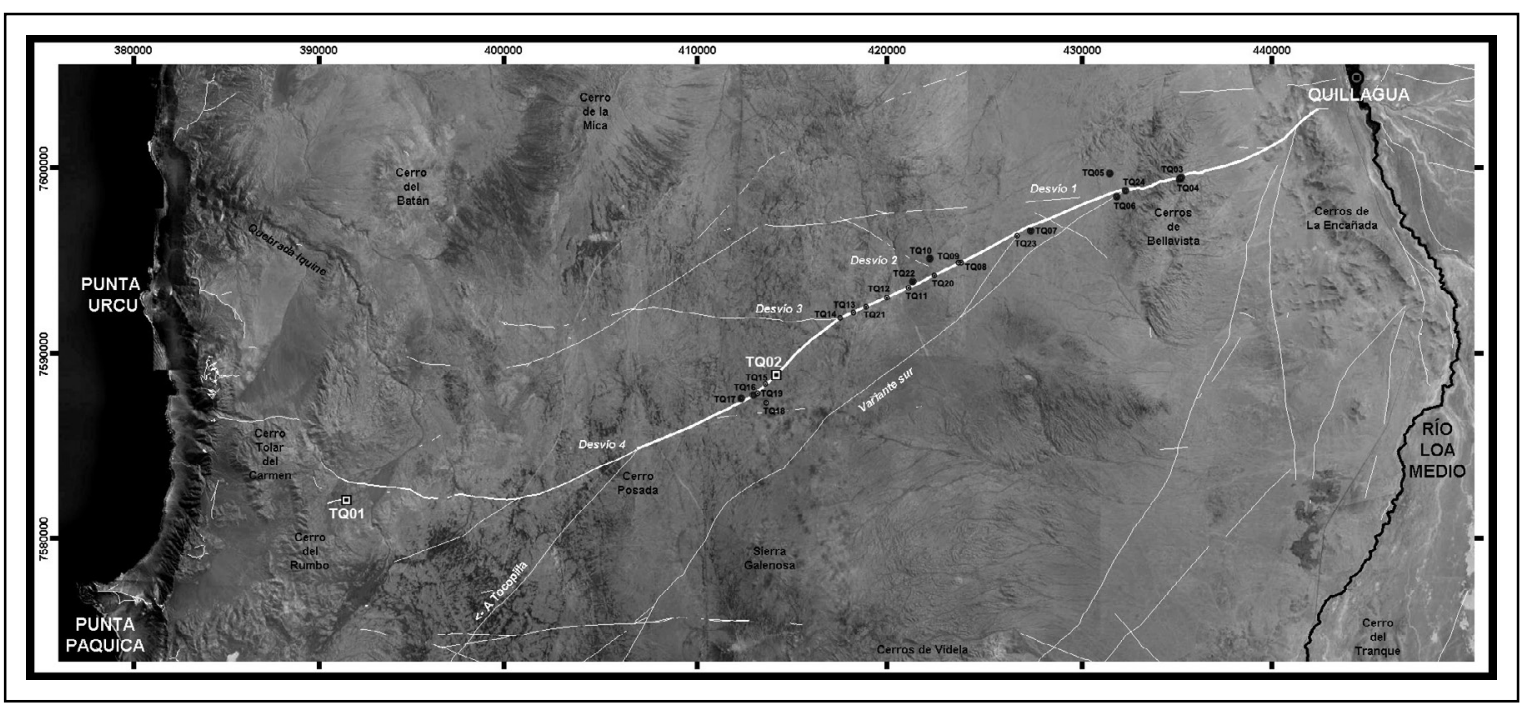

Figura 2. Internodo en estudio, ruta Tocopilla-Quillagua (TQ). Al centro, la ruta estudiada. En trazo blanco grueso la sección de vía múltiple, en trazo medio la vía simple (desvío 4). Se indican con líneas finas otras secciones de huella conocidas. Los cuadrados indican las "ocupaciones extractivas"; los círculos gruesos, geoglifos, los círculos pequeños, estructuras de pernocte.

wSe identificaron dentro del sitio siete (7) sectores principales (Figura 3a). La suma total de las áreas modificadas por las extracciones mineras en estos sectores es de $2.089 \mathrm{~m}^{2}$. Relevados los distintos piques mineros, se constató su heterogeneidad tipológica, es decir, la presencia de extracciones subcirculares, alargadas y rajos de distinta extensión y profundidad. Respecto de esta tipología, debe anotarse que las alargadas tienen un aspecto oval o elipsoidal y que usualmente son agregados de extracciones subcirculares adyacentes, cuyos bordes se obliteran entre sí. Las excavaciones en rajo son, por otra parte, realizadas con esa morfología directamente y con frecuencia presentan desmontes de talud, cuya forma en sección lateral es similar a una cuña. Hay algunos pocos casos en que este tipo de excavación presenta características de trabajo semisubterráneo, mostrando las oquedades un "techo" pequeño o ceja (Figura 3b).

La presencia de sedimentos eólicos acumulados en el fondo de las extracciones impide saber la magnitud exacta del trabajo realizado en tiempos prehistóricos, pero una primera aproximación al volumen de material extraído, modelado desde formas geométricas simples (cono, volumen triangular y volumen rectangular) nos indica un mínimo general de $607,37 \mathrm{~m}^{3}$, lo cual, comparado con la densidad absoluta de una muestra del material obtenido (un bloque de $5 \mathrm{~kg}$ obtenido del perfil de uno de los rajos), supone la extracción de al menos 543 toneladas de mate- rial durante la historia de uso de la mina. Un resumen general de las características de la mina y sus materiales en superficie pueden consultarse en la Tabla 2 y Figura 3.

En cuanto a los ítems culturales, se constató la presencia de bastante material asociado a las extracciones (Tabla 2), consistente en restos de martillos líticos y sus lascas; conchas marinas con modificaciones por uso y fragmentos variados, principalmente de loco (Concholepas concholepas), choro zapato (Choromitylus chorus) y erizo (Loxechinus albus); y restos de madera de cactus (probablemente Eulychnia iquiquensis). Todo lo anterior fue encontrado también, aunque en fragmentos muy pequeños, en estratigrafía.

La mayor parte de los instrumentos líticos son nódulos alargados con erosión de rodado marino, de gran tamaño y masa, de andesita y basalto. Por ejemplo, los cinco nódulos de la fila superior de la Figura 3c, pesan 4.8, 4, 2, 1 y 1.3 $\mathrm{kg}$, respectivamente. Al no presentar huellas de enmangue, presumimos que se emplearon con prensión manual directa. Su forma y material implican que solo pueden haber sido obtenidos en la costa. Hay muy pocas excepciones a esta norma, que son restos de martillos de materiales probablemente procedentes de la misma cordillera de la Costa (Figura 3 c abajo, extremo izquierdo y derecho), lo cual se infiere del aspecto macroscópico de su corteza, que presenta abundante barniz o "pátina del desierto" (Liu y Broecker 2007; Dorn 2009). Los desechos líticos 


\begin{tabular}{|c|c|c|c|c|c|c|c|c|c|c|c|c|c|c|c|c|c|c|c|c|c|c|c|}
\hline \multirow[b]{2}{*}{ Sector } & \multicolumn{3}{|c|}{ Extracciones } & \multicolumn{6}{|c|}{ Datos por tipo de extracción } & \multicolumn{3}{|c|}{ Materialidad } & \multicolumn{6}{|c|}{ Materiales por asociación } & \multirow[b]{2}{*}{ 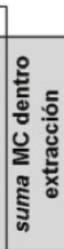 } & \multirow[b]{2}{*}{ 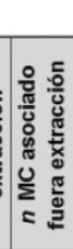 } & \multirow[b]{2}{*}{$\begin{array}{l}\frac{0}{\frac{\pi}{0}} \\
\frac{\pi}{00} \\
\frac{0}{4} \\
0 \\
\frac{0}{\Sigma} \\
=\end{array}$} & \multirow[b]{2}{*}{ 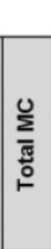 } & \multirow[b]{2}{*}{$\frac{\bar{\varrho}}{\frac{0}{\Sigma}}$} \\
\hline & 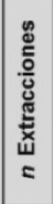 & 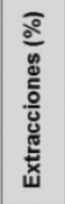 & 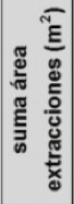 & 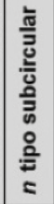 & 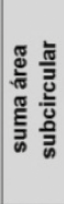 & $\begin{array}{l}\text { 음 } \\
\text { 을 } \\
ㄷ\end{array}$ & 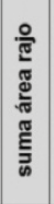 & 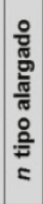 & 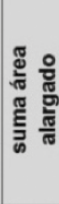 & 总 & 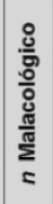 & : & 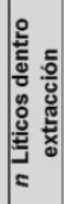 & 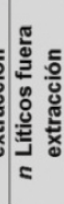 & 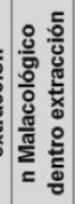 & 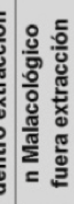 & 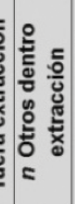 & 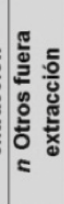 & & & & & \\
\hline 01) Norte cerro & 47 & 29,9 & 534,4 & 43 & 468 & 0 & 0 & 4 & 66,2 & 2 & 1 & 1 & 0 & 1 & 1 & 1 & 1 & 0 & 2 & 2 & 0 & 4 & 2,4 \\
\hline 02) Talud Oeste cerro & 8 & 5,1 & 127,6 & 1 & 7 & 7 & 128 & 0 & 0 & 25 & 39 & 8 & 1 & 23 & 6 & 36 & 3 & 3 & 10 & 62 & 0 & 72 & 44 \\
\hline 03) Cima de cerro & 17 & 10,8 & 140,9 & 9 & 56,1 & 8 & 85 & 0 & 0 & 2 & 2 & 2 & 0 & 0 & 0 & 1 & 0 & 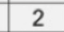 & 0 & 3 & 3 & 6 & 3,7 \\
\hline 04) Talud Este cerro & 19 & 12,1 & 147 & 9 & 50,5 & 9 & 85 & 1 & 11,8 & 1 & 4 & 1 & 0 & 0 & 2 & 2 & 1 & 0 & 3 & 2 & 1 & 6 & 3,7 \\
\hline 05) Loma NW & 14 & 8,92 & 355,3 & 11 & 118 & 0 & 0 & 3 & 238 & 11 & 14 & 5 & 8 & 5 & 8 & 5 & 2 & 2 & 18 & 12 & 0 & 30 & 17 \\
\hline 06) Loma SW & 45 & 28,7 & 561,3 & 32 & 285 & 9 & 185 & 4 & 91,4 & 4 & 36 & 1 & 1 & 3 & 9 & 18 & 0 & 0 & 10 & 21 & 10 & 41 & 25 \\
\hline 07) Sur cerro & 4 & 1,91 & 67,8 & 1 & 4,7 & 2 & 16 & 1 & 47,5 & 1 & 1 & 1 & 0 & 0 & 4 & 0 & 1 & 0 & 2 & 0 & 1 & 3 & 1,8 \\
\hline \begin{tabular}{|l|} 
Aislados \\
\end{tabular} & 4 & 2,55 & 155,1 & 2 & 113 & 2 & 42 & 0 & 0 & 0 & 4 & 0 & 0 & 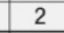 & 0 & 2 & 0 & 0 & 0 & 4 & 0 & 4 & 2,4 \\
\hline TOTALES & 158 & 100 & 2089 & 108 & 1102 & 37 & 539 & 13 & 455 & 46 & 101 & 19 & 10 & 34 & 27 & 65 & 8 & 7 & 45 & 106 & 15 & 166 & 100 \\
\hline
\end{tabular}

Tabla 2. Relación cuantitativa general de extracciones y materiales en superficie en TQo1.

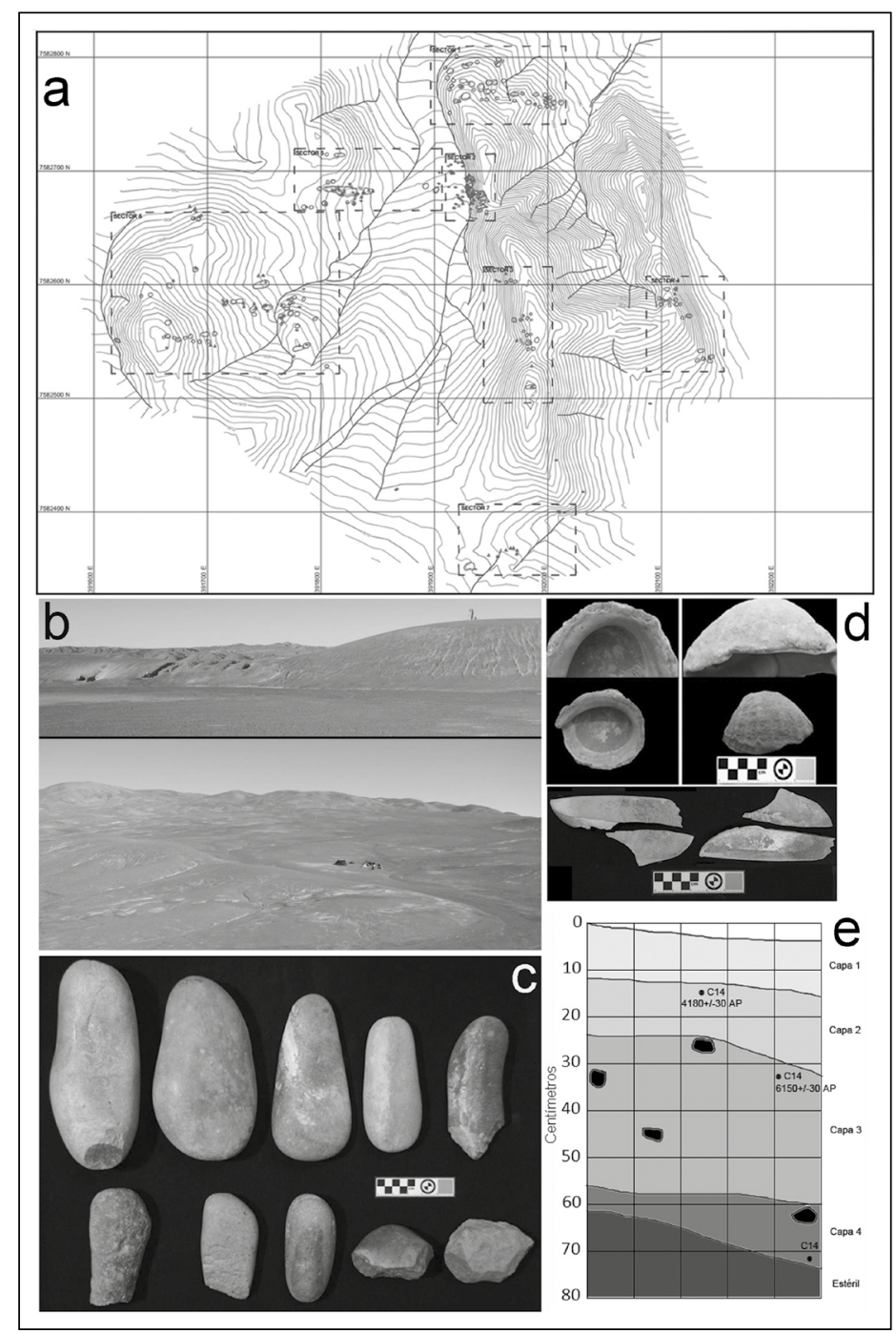

Figura 3. Vista de la mina, materiales líticos y conquiológicos. 
recuperados pertenecen en su mayoría a lascas corticales desprendidas de las áreas de impacto en los extremos de los martillos de materia prima costera. Es interesante notar que algunos espacios de la mina TQor han sido equipados con instrumentos, como nos revela un "caché" constituido por las piezas 4 y 5 , las dos de la derecha en la Figura 3 f fila superior. También, resulta de interés indicar que no existen estructuras de pernocte reconocibles.

Respecto de las piezas que pueden asignarse a instrumentos conquiológicos, un examen macroscópico de los bordes (lupa binocular de 1oX) arrojó modificaciones en 32 casos, distribuidas principalmente entre $C$. Chorus y $C$. Concholepas, y un caso en concha de lapa (Fissurella latimarginata). La función inferida de estas piezas es de pala manual en ambos casos, debido a la identificación de desgaste y microastillamiento de los bordes (Figura 3d).

La excavación de sondeo realizada, fue una unidad de $50 \times 50 \mathrm{~cm}$, dispuesta sobre el talud generado por los desechos de la extracción en el acceso al rajo más grande, y presentó cuatro capas con un máximo de profundidad de $70 \mathrm{~cm}$. Se obtuvo material para fechar en las capas 2,3 y 4 , dando resultados de $4180 \pm 30$ y $6150 \pm 30 \mathrm{AP}$ (Beta 322324 y 322325 ), para las dos primeras, correspondientes a los Períodos Arcaico Tardío y Medio, en tanto que lamentablemente, el fondo de la ocupación, representado por una vértebra de pescado, no presentó colágeno suficiente para la fecha, restando aproximadamente $35 \mathrm{~cm}$ de depósito por datar. Puede consultarse la situación estratigráfica de los fechados en la Figura ze. Por otra parte, llama la atención en la Capa 3, la presencia de un pequeño fragmento de mineral de cobre. Los datos precedentes parecen sugerir que las propias extracciones mineras pudieron haber sido utilizadas como lugares de pernocte.

En términos geológicos, el manto explotado en la mina es de carácter reciente, quizá Plio-Pleistocénico, y pudiera estar relacionado con procesos genéticos similares a los del lago Soledad (cf. Naranjo y Paskoff 1982), pero en este caso, asociados a una paleocuenca con drenaje al norte en la cima de la cordillera de la Costa, tras la cortina hídrica que supone la primera línea de cumbres, constituidas de norte a sur por los cerros del Batán, Tolar del Carmen, Del Rumbo y Tolar. Se encuentra constituido por depósitos de 20 a $80 \mathrm{~cm}$ de espesor de esta sustancia blanca de carácter evaporítico y de granulometría muy fina, con escasas y pequeñas inclusiones rocosas.

La formación de salares y cuerpos sedimentarios como el que nos interesa, está condicionada por un proceso de precipitado natural con una secuencia definida, en que los materiales de las capas superiores están conformados por halitas, luego los sulfatos (este caso), carbonatos, nitratos y boratos (ver Stoertz y Ericksen 1974, Pueyo et al. 1998). Los análisis realizados al material fueron de tres tipos distintos. Primero, por microscopía binocular cuyo informe afirmó nuestro postulado de que se trataba de yeso, aunque uno de los analistas agregó que la muestra también podría contener alguna clase de aluminato, sin mayores precisiones. Luego, se realizó una espectroscopía RAMAN, cuyo resultado confirmó que el sulfato de calcio $\left(\mathrm{CaSO}_{4} \mathrm{O} \mathrm{CaSO}_{4}-2 \mathrm{H}_{2} \mathrm{O}\right.$, anhidrita o yeso) era, efectivamente, un componente principal de la sustancia, produciéndose un importante peak en la wavenumber $1008 \mathrm{~cm}^{-1}$, conocida desde hace largo rato en la bibliografía como sintomática de $\mathrm{CaSO}_{4}$ (Bhagavantam 1938). Esto fue sostenido independientemente por un análisis por pXRF en un laboratorio distinto.

Por último, realizamos un pequeño experimento para estimar cuánto trabajo y tiempo podría tomar la molienda y el separado de la ganga del material extraído, empleando un martillo de piedra de características similares a los hallados, de dos manos, para reducir a polvo nuestro bloque de muestra. Esta operación, la reducción y molienda de 6 $\mathrm{kg}$ de yeso, tomó 29 minutos y requirió 306 impactos del percutor (alzar y dejar caer), 174 acciones de molido (alzar, dejar caer y pivotear el percutor sobre el sedimento) y 36 secuencias de arreglo del montón de sedimento molido, con tiempos y cantidad de acciones variables. Para esto, nos ayudamos con una espátula, que hizo las veces de pala, como suponemos que se usaron las conchas recuperadas. El proceso de embolsado tomó 61 acciones (llenar la espátula y meter en la bolsa). Contra nuestras expectativas, resultó que la cantidad de "ganga" era mucho menor a la imaginada, totalizando para la muestra 26 gramos representados en 11 fragmentos de roca, algo así como un $0,24 \%$ del peso del sedimento en su estado natural. 


\section{TQO2 "paskana-taller"}

Este segundo sitio extractivo se encuentra prácticamente a mitad de camino entre la costa y Quillagua, a unos 45 $\mathrm{km}$ de ambos lugares siguiendo la huella prehispánica. Destaca su posición $2,9 \mathrm{~km}$ al este de la falla de Atacama. Su altitud es de $1643 \mathrm{msnm}$. Se trata de la estribación sur de un pequeño cerro rodeado hacia el noroeste de la locación del sitio por detrito rocoso tabular. Presenta seis paskanas en depresión por la ladera noreste. La huella, en este punto de la vía es de tipo múltiple, con cerca de $6 \mathrm{~m}$ de ancho en algunos lugares (Figura 2 y Figura 4a).

En TQ02 se recuperaron en superficie diversos materiales líticos, hojas de palas o azadas, hachas, cepillos, martillos y otros artefactos (ver Figuras $4 \mathrm{~d}$ y $4 \mathrm{e}$ ), notablemente una especie de "paleta" hallada en directa asociación con los paneles de geoglifos, que podría tratarse del instrumento empleado para su ejecución si consideramos sus microastilladuras en el filo. ${ }^{13}$ Se recolectaron 43 elementos instrumentales de un total de 200 identificados y georreferenciados en el lugar (21,5\%). Existen abundantes desechos de talla, pero solo se recuperaron los correspondientes a la unidad de sondeo practicada, como se indica más adelante.

En general, todo este instrumental se manifiesta como preformas fracturadas que presentan talla bimarginal por su perímetro. En el caso de las palas, destacan los casos en que se realizó "hombros" simétricos para la sujeción de las piezas a un mango. Las placas sobre las cuales se confeccionaron presentan corteza por sus dos caras en todos los casos. Si bien se recuperaron pocos especímenes completos, pudo constatarse que presentan pedúnculos de entre 10 y $15 \mathrm{~cm}$ de largo, con un ancho de entre 5 y $8 \mathrm{~cm}$. Tratándose de piezas fracturadas, no es posible indicar cuáles son las dimensiones de las hojas de las palas, salvo por su ancho, que promedia los $14 \mathrm{~cm}$. Es decir, se trataría de palas de pequeñas dimensiones. Por otra parte, se encontraron cuatro piezas que representan, a nuestro entender, hachas de piedra o cuñas de alguna clase (hay en todo caso, seis fragmentos más que podrían corresponder a esta clase morfo-funcional).

13 Este fue el único elemento que presentaba huellas de uso, pues, presumiblemente fue el único efectivamente empleado en el sitio. El resto de las piezas corresponde a descartes y preformas.
Éstas se caracterizan por poseer tres lados de corte recto y uno biselado por percusión bimarginal. Han sido ejecutadas sobre un nódulo tabular de sección transversal triangular elongada, con el filo modificado en el extremo más agudo, aparentemente a modo de robustecer el filo. Respecto de los martillos y/o percutores, solo puede indicarse que presentan enorme variabilidad, habiendo sido seleccionados de entre los nódulos tabulares más gruesos disponibles en el afloramiento. El resto de las categorías morfo-funcionales son escasas y bastante menos formales que las anteriores. En resumen, todo el material lítico recuperado en superficie corresponde al mismo material que allí aflora.

A pesar de que faltan mayores precisiones de carácter geológico por realizar, la roca explotada sería una andesita tabular, cuyo análisis por pXRF describió como un material abundante en hierro, que no puede obtenerse en ningún otro lugar a lo largo de toda la vía prospectada.

El sitio presenta también dos paneles de geoglifos, sobre una pendiente suave y muy cerca de las paskanas, siendo inusual la asociación de este tipo de arte rupestre con sitios de carácter extractivo (Figura 4a). El Panel 1, que mira hacia la costa, presenta motivos abstractos que no tienen, hasta donde sabemos, símil en otros casos de la región. Por su parte, el Panel 2, que mira hacia Quillagua, presenta un rombo escalerado y una cruz con puntos que tendrían que referirse al Período Intermedio Tardío, según la literatura (ver p.e. Pimentel 2011).

También se recuperó cerámica asociada a la vía de circulación, en tres loci separados, además de un fragmento cerámico que se encontró depositado al interior del Motivo 4 del geoglifo en la cara $\mathrm{E}$ de la pequeña elevación que contiene al sitio. En total, se trata de 11 fragmentos correspondientes a tres vasijas cerámicas (Figura 4b), principalmente de tipos propios del Período Formativo Tardío relacionados a la tradición cerámica QuillaguaTarapacá (Componente Tarapacá): QTC (Quillagua Tarapacá Café Amarillento) y QRP (Quillagua Rojo Pulido). Ocho fragmentos corresponden a este último tipo y se derivan de la fractura de un pequeño jarro. Cronológicamente, esta tradición cerámica se sitúa entre el 600 y 950 DC (Agüero et al. 2001; Méndez-Quirós y Uribe 


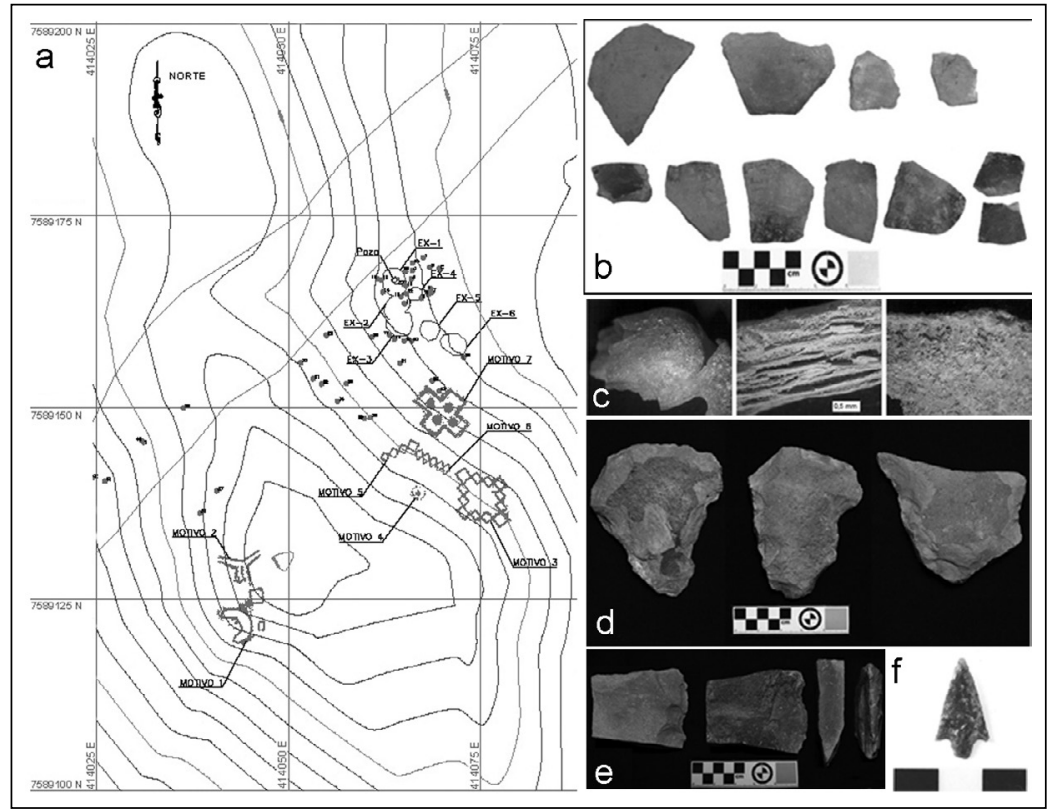

Figura 4. Levantamiento topográfico y materiales de TQO2.

2010; Uribe y Vidal 2012), ${ }^{14}$ traslapándose sus momentos tardíos con el Período Intermedio Tardío (PIT). La excepción es precisamente la pieza asociada directamente al geoglifo, un único fragmento de cuerpo de una botella del tipo PCH (Pica-Charcollo), distintivo por su característico tratamiento de superficie ("escobillado") y por restos del engobe fugitivo rojizo en exterior, cuyas fechas tienen un peak cercano al 1200 DC (Uribe et al. 2007) (ver Figura 4b) .

El material obtenido en la excavación de sondeo de una de las paskanas en depresión consistió en fragmentos pequeños de maíz (Zea mays), endocarpos y madera de algarrobo (Prosopis sp.), un fragmento de crustáceo dulceacuícola (probablemente Cryphiops caementarius), como se aprecia en la Figura 4c. También se obtuvieron fecas de camélido, plumas, dos lascas pequeñas de retoque por presión, varias lascas mayores de la elaboración de los instrumentos "de labranza" mencionados y una punta pequeña triangular pedunculada con aletas, típica del

14 En Quillagua presenta fechas de 660 DC (Qui-89) y 665 DC (Qui-84) (Agüero et al. 2001), y en Tarapacá de 970 DC (Caserones 1) (Méndez-Quirós y Uribe 2010), con posibles fechas más tempranas cercanas al 200 DC, en contextos de Quillagua y Pisagua (Uribe y Vidal 2012).
PIT en adelante (Figura 4f), confeccionada en una de las variedades de calcedonia del oasis de Quillagua. La datación que obtuvimos de la excavación fue consistente con esto último, entregando una fecha de $390 \pm 30 \mathrm{AP}$ (Beta 334313, semilla de algarrobo), 1560 DC, Período Tardío. Esta fecha, calibrada, entrega un rango dividido de $1440-$ 1520 y $1570-1590$ Cal. DC. Suponemos más probable el rango inferior.

\section{* Discusión}

El registro de "ocupación extractiva" de los Períodos Arcaico Medio y Tardío (6000-400o AP) identificado en la ruta TQ confirma la hipótesis de que las vías de movilidad al interior del desierto ya estaban articuladas en este período, al menos para un aprovisionamiento logístico. A pesar de que no existe otro registro publicado con las características de lo identificado en TQol, cada vez hay más casos, aún inéditos que confirman lo anterior. ${ }^{15}$

Desde un punto de vista diacrítico, este sitio representa exclusivamente una agencia costera, sin que se haya en-

15 Conocemos actualmente 15 casos más, que esperan por una sistematización y correlación. 
contrado entre sus materiales elementos que correspondan a personas oriundas de espacios de tierra interior. Es extraordinario que la "ocupación extractiva" descrita se trate de yeso, pues este material no ha sido descrito en la bibliografía como parte del panorama económico de estas poblaciones costeras a nivel regional. Hasta donde sabemos, se trata de la única mina de yeso conocida para poblaciones de cazadores recolectores marinos y, además, de la mina de este material con fechas más tempranas a nivel mundial, aunque existen ejemplos en Egipto de ca. $4500 \mathrm{AP}$ (Heldal et al. 2009) y en Norteamérica de ca. 3000-1000 AP (p.e. Kennedy y Watson 1997). Es importante recordar que recientemente en el mismo desierto de Atacama, se ha descubierto e investigado una mina de Ocre rojo, con fechas desde ca. $10100 \mathrm{AP}$, por lo cual suponemos que el segmento no datado de la estratigrafía de TQo1 podría, eventualmente, llevarnos a fechas similares en el Período Arcaico Temprano. En esta otra mina, San Ramón-15, en Taltal, se recuperaron materiales para la extracción (martillos) muy similares a los nuestros (Salazar et al. 2011, 2013)

A pesar de la escasez de datos arqueológicos para interpretar cuál o cuáles fueron los propósitos para los que se extrajo esta enorme cantidad de yeso, fuentes arqueológicas y etnográficas, nos permiten proponer varias hipótesis de su posible uso, que presentamos aquí ordenadas de forma intuitiva en cuanto a su probabilidad:

1) Uso para pintura corporal. Existe un ejemplo de pintura corporal con color asimilable al del yeso del sitio TQor en momias Chinchorro. Esta pintura corresponde a listas transversales al cuerpo, en el sitio Maderas Enco, Arica (Arriaza y Standen 2008: 103). Ejemplos etnográficos geográficamente distantes pero evocadores son las pinturas corporales de los Selk'nam de Tierra del Fuego: "Para realizar pinturas ornamentales se tiene en mucho el yeso fino de un paraje... que lleva el nombre de [káixtem] y era un objeto de trueque. De un terrón del tamaño de un puño se raspa un poco de polvo con los dientes, se mezcla bien con saliva en la boca y se usa como colorante" (Gusinde 1982: 206).

2) Consumo humano de sedimentos (geofagia). Este fenómeno presenta tres hipótesis para explicar su desarrollo evolutivo en los seres humanos: 2a) Deficiencias nutricionales, especialmente de hierro y zinc; 2 b) Protec- ción, para reducir los efectos de químicos dañinos, parásitos y patógenos; $y, 2 c$ ) No adaptativa, para reducir los efectos del hambre cuando no hay comida disponible o como epifenómeno derivado de deficiencias nutricionales. (Young et al. 2011: 98-99).

Análisis de coprolitos humanos de sitios precerámicos del centro norte de la costa de Perú, fechados entre al menos 4500 y 3500 años AP (y posiblemente de hasta $6000 \mathrm{AP})$, detectaron una

...relativamente alta proporción de tierra y arena que se encontró en algunas muestras de esta época. Esto sugiere la posibilidad de geofagia (práctica que a veces recibe el nombre de "pica") que pudiera haber sido practicada por razones medicinales o para rellenar el estómago en algún momento por falta de comida...

Comer tierra, o "pica", es una práctica conocida en poblaciones tropicales para curar ciertas enfermedades como la anemia causada por lombrices intestinales y pudo haber sido aplicada también en el pasado. En este sentido, el hallazgo de endoparásitos en coprolitos de Los Gavilanes, a pesar de que son ligeramente posteriores en el tiempo, por lo menos dejan abierta esta posibilidad... (Weir y Bonavia 1985: 98-99). ${ }^{16}$

Nos parece de mucho interés la explicación referida a protección contra parásitos, que, efectivamente, han sido identificados con importante prevalencia en momias Chinchorro en Arica y en otras poblaciones de la región (Arriaza y Standen 2008; Fouant et al. 1982; Iñíguez et al. 2003), llegándose a plantear una zoonosis variable relacionada con el fenómeno de El Niño que afectó a las poblaciones Chinchorro (Arriaza et al. 2010). Cabe destacar que las poblaciones que nos interesan estaban amplia y frecuentemente expuestas al contagio de Diphyllobothriasis y Anisakiasis, las que han sido documentadas como frecuentes en peces, crustáceos y mamíferos marinos (p.e. George-Nascimento y Carvajal 1981). En este caso, nuestros sedimentos podrían haber funcionado como bloqueadores de la implantación de los parásitos intestinales en el huésped.

16 Por economía de espacio hemos eliminado de la transcripción las abundantes citas de estos autores. Para mayor detalle, ver también la versión ampliada de estos trabajos publicada en Bonavia et al. (1993). 
Estudios etnográficos en el altiplano (Browman y Gundersen 1993; Browman 2004), también sugieren funciones medicinales y nutricias de la geofagia, ya que existen alrededor de 24 tipos de tierras frecuentemente consumidas por poblaciones indígenas, de las cuales destaca, por ejemplo:

[el] r) mullu, piedra berenguela, pachas, pachach, pachacha, pahachi, poke lomanake. Los vendedores del mercado usaron el termino mullu para referirse a yeso; no obstante, otras fuentes ofrecen otros nombres como alternativa. El análisis de DRX de nuestra muestra (procedente de Oruro) la identificó como un típico hidrato de sulfato de calcio... Se utiliza para hacer illas, para proteger y curar, para tratar males relacionados con el susto y el aire, para proteger de los rayos, maldiciones y espíritus malignos, así como para detener hemorragias fuertes (Browman 2004: 139).

Los ejemplos prehistóricos geográficamente más cercanos con los que contamos para consumo humano de sedimentos minerales son, en todo caso, los del Formativo de Arica, con influencia Tiawanaku (400-800 DC), donde en AZ-6, Focacci (1990) describe:

Upi. A veces ubicamos en las bolsitas de lana, con la sorona, el maíz u otros comestibles, unos panes de arcilla blanca, casi del tamaño del dedo gordo de una persona adulta. Una pasta similar es denominada por los regionales altiplánicos upi, y se usa en la alimentación en forma de una masa blanca arcillosa que se agrega a las papas cocidas para comerlas" (op. cit.: 78).

También es posible que los paquetes con sedimentos de Patillos (Olmos y Sanhueza 1984) en contexto Chinchorro correspondan a esta práctica iniciada con mucha anterioridad.

3) Uso arquitectónico. A partir del $5500 \mathrm{AP}$, se ha reportado para el Arcaico Tardío la presencia de distintos sitios "semi-aldeanos", en toda la costa arreica entre la desembocadura del Loa y Taltal (Núñez et al. 1975, Contreras et al. 2007, entre otros), los cuales presentan una arquitectura con uso de cementos y argamasas para la preparación de muros y pisos. Una de las primeras menciones es la de Schaedel (1957) para Punta Guasilla, al sur de Cobija, donde las estructuras se caracterizan “...por el empleo del cemento de ceniza y huiro" (p. 25). El ejemplo más conocido de esto, proviene de Cah-42 donde "Para pegar las piedras se utilizó argamasa de ceniza de algas con conchuela y otros desechos. En el interior encontramos pisos de ceniza de alga que sirvieron para sellar los enterramientos. En la estructura 1 se encontraron 4 de estos pisos-sello." (P. Núñez 1974: 29). La idea de que se trata de cenizas de algas mezcladas con agua marina es una explicación tentativa que se ha asumido como plausible con poca exploración analítica de su detalle, a excepción de una experimentación realizada mezclando cenizas de huiro quemado, arena, conchilla y agua de mar, lográndose una composición muy parecida a la de los pisos de caleta Huelén 42 (en Montenegro 1982: 65). En nota al pie, Montenegro (1982) indica que "Esta mezcla se hace hoy en día por los Changos locales, en Punta Guasilla, a pocos metros del sitio" (op. cit.: 65), lo cual implica una analogía etnográfica de más de 7000 años de antigüedad que habría que reevaluar a futuro. Finalmente, en referencia a las algas y los pisos, Montenegro (1982) indica: “...no hay evidencia que nos conduzca a afirmar con certeza la presencia de algas como componente en la mezcla del piso señalado" (op. cit.: 65).

Volviendo al área de estudio, en Quillagua existe una mención al yeso, pero del Período Formativo en adelante, fuera del rango temporal de TQo1: "Las ruinas consisten en una serie de muros y pircas de piedra y argamasa de greda revuelta con yeso" (Latcham 1933: 133; Cervellino y Téllez 1980).

En suma, bien podría tratarse en el caso de algunas de las argamasas mencionadas, o parte de la composición de ellas, de materiales como el yeso de la mina TQoı, cuestión que deberá ser examinada más detenidamente en el futuro por nuevas investigaciones.

4) Uso como material funerario. Son frecuentes en la literatura del Período Arcaico Medio y Tardío de la costa desértica, las referencias a tradiciones funerarias diferenciadas de las áreas al sur y al norte del río Loa. Al norte, se conocen entierros Chinchorro como los de Patillos, ya mencionados. Al sur, los entierros presentan manipulación secundaria en estructuras habitacionales y entierros cubiertos de barro en conchales. Esta tradición tiene íntima relación con la arquitectura y considera el enterramiento sucesivo, quizás con remociones reiteradas de individuos o sus partes bajo los pisos de las estructuras habitacionales. Esto podría haber requerido la reparación de pisos, utilizando por ejemplo yeso, cada vez que se rea- 
lizaba esta operación. También, en caleta Huelén 42 se encontró bajo los pisos-sellos enterramientos cuyo ajuar se calificó como "chinchorroide", que en términos de su preparación se expresa en un ejemplo “...incluyendo pintura y arcilla en las cavidades orbitales..." (Núñez, L. 1972: 17, también P. Núñez 1974: 30), lo que indica la inclusión activa de sedimentos minerales en el proceso funerario.

5) Como material para la preparación de cueros. Destaca en este caso, una cita de Arce (1997 [1930]), quien indica:

Hasta los changos de la costa... se internaron en las serranías de Huacate, en el actual departamento del Loa, para extraer de la alcaparrosa, la pintura roja que resulta, después de la calcinación, especie de betún con que embadurnaban sus balsas de cuero para protegerlas de la "broma", gusano que destruye las embarcaciones que ellos utilizaban en su original y rutinaria industria de la pesca (op. cit: 416).

Aunque de carácter histórico, esta cita permite ponderar la importancia de los sedimentos minerales que habría justificado plenamente viajes al interior del desierto, incluso más largos que lo necesario para ir de Tocopilla a Quillagua; del mismo modo permite referirnos a las posibles primeras tecnologías "anti-fouling" de la prehistoria chilena. Al respecto,

Los efectos de la corrupción han sido solo recientemente sujeto de pesquisas cientificas sistemáticas. Su seriedad, en todo caso, ha sido reconocida desde tiempos muy antiguos. Aunque se han hallado registros escritos del tratamiento del fondo de naves tan tempranos como el siglo V a.C., la búsqueda por superficies incorruptibles sin duda comenzó con naves aún más tempranas de los cuales tenemos poca información ${ }^{17}$ (WHOI 1952: 211).

6) Como elemento de aseo. La lectura de los trabajos de Gusinde (1982) acerca de los Selk'nam, nuevamente guardando la cautela que una analogía semejante representa, incluye aun otra posibilidad en el uso de sedimentos blanquecinos a modo de "jabón", para el aseo personal (op. cit:: 207), y especialmente para el de neonatos e infantes (el término es "[kome]", op. cit.: 344-5).

A pesar de que solo un análisis detallado de áreas habitacionales, funerarias, caminos y minas en la costa $y$

17 La traducción es nuestra. en el desierto, podrá en el futuro realizar proposiciones más seguras sobre el uso del yeso en la prehistoria de la zona de estudio, nos parece que la utilidad de este material del sitio TQor podría involucrar varios de los ámbitos mencionados.

Más allá de las importantes implicancias que tenga el uso e importancia del yeso para los grupos humanos que habitaron el desierto de Atacama, para futuras investigaciones arqueológicas, desde el presente caso de estudio puede proponerse que: 1) la movilidad costera pedestre al interior del desierto tiene raíces Arcaicas; 2) que esta movilidad generó una red vial que subsiste todavía en algunos lugares $y, 3$ ) que en el caso del desierto bajo de Atacama, se produjo sobre la base del aprovisionamiento de materiales minerales de forma redundante durante muchas generaciones, configurando un "viaje" que habría tomado entre 3 y 5 días. También, que dicho viaje implicaba provisiones para ese período y el equipamiento con herramientas específicas para la actividad. Estas ideas se robustecen si sumamos a este caso, el previamente detectado en la Pampa El Toco, de aprovisionamiento lítico basado en grandes bifaces asociado a una huella simple pedestre (Blanco et al. 2010). Puede decirse también que esta movilidad es de tipo logística, según se entiende normalmente en la tradicional arqueología de cazadores-recolectores. Generalizaremos respecto de esta modalidad de movilidad costera arcaica más adelante, cuando discutamos el modelo previamente presentado como referencia. Cabe notar que, aunque el estudio de la mina se inscribió dentro de una "perspectiva internodal", los límites de ésta con la "arqueología de la minería" en este caso de estudio son casi inexistentes, por lo cual, no obstante, se podrían realizar nuevos estudios referidos al tema dentro de esta perspectiva, haciéndonos eco de lo señalado como programáticamente importante por Salazar y Vilches (2014). Más adelante hacemos un breve excursus relativo a esto (Figura 5), en la forma de una comparación de los registros obtenidos en el marco de un modelo procedente de los estudios mineros.

Por otro lado, el sitio "Paskana-Taller" TQO2 presenta un caso que puede entenderse como diametralmente opuesto. Se trata de un ejemplo de movilidad caravanera, pero con la particularidad de presentar la asociación de una actividad extractiva como es la de talla lítica de instru- 
mentos de labranza. En este caso, se configura lo que podríamos llamar una "ocupación tránsito-extractiva", pues incluye "...vestigios vinculados con la extracción de recursos del internodo "al pasar"." (Nielsen 2006: 35). En este sentido, en Atacama, solo se conoce una asociación semejante entre vías y manufactura de instrumentos (mineros) en el sitio Chu-2 (Núñez et al. 2003: 13), pero sin geoglifos.

En el sitio TQO2 se ha documentado la presencia de una extracción de placas líticas de una andesita o basalto ferroso, destinada a la confección de "instrumentos de labranza", con una fecha de ca. 1560, Período Tardío. En general, las palas han sido asociadas a actividades agrícolas, los martillos a la minería, en tanto que las hachas nos hablan de actividad forestal.

Los trabajos específicamente dedicados al tema de las palas líticas provienen, todos, de la vertiente oriental de la cordillera, destacando por su nivel de detalle analítico los de Román Gastaldi (2007), para las palas de Tebenquiche Chico, desde un enfoque multidimensional; los de Pérez (zo10a y b), para Casa Chávez Montículos y Doncellas, desde la organización tecnológica; o los de Ávalos (1998) con interesantes aportes experimentales. La discusión de este tema es antigua en la arqueología de esa región y hay muchas fuentes relevantes. En la vertiente occidental, por su parte, el tema específico ha sido poco estudiado, pero hay -como veremos- abundantes datos disponibles. No está de más decir que se requieren más trabajos específicamente orientados al tema, desde perspectivas complementarias, que podrán proveernos de "tierra fértil" que articule mejor estas piezas con la prehistoria.

La sola presencia de palas en TQO2 es consistente con la fecha obtenida de la paskana, aunque no es muy novedosa, siendo conocidos ejemplos de estas piezas para toda la región atacameña, del Período Formativo en adelante (p.e. Pollard 1970; Spahni 1964; González y Westfall 2010). En todo caso, sí se trata de un registro novedoso para Quillagua, donde hasta ahora no había sido reportada la presencia de palas líticas (o de hachas y martillos), a pesar de todos los trabajos arqueológicos conocidos (vide supra). Las únicas palas que se conocen de Quillagua son las de madera reportadas por Latcham (1933: 136).
Debe destacarse, a este respecto, que todas las palas líticas con fechas Formativas tempranas y medias, son rectangulares, alargadas o con el pedúnculo muy levemente enunciado, por lo cual quizás debieran pensarse como "azadas". En contraste, las palas a partir del Formativo Tardío (ca. 800 DC), presentan un pedúnculo bien marcado, muchas veces con hombro en ángulo, con la hoja de forma general triangular apuntada, con expresión más fuerte durante el Período Intermedio Tardío y el Tardío. También se nota que son más propias de tierras altas, aunque puede tratarse de un sesgo asociado a la mayor investigación en estos espacios. Al respecto, sirven de referencia los trabajos de Vásquez (2005), para el pukara de Turi y sus alrededores; el de Uribe y Carrasco (1999), para Caspana; y los del mismo Pollard (1970), en referencia a sus Fases Loa I y II, y complejos Turi y Lasana, para el Loa superior. También Méndez (2007), en un trabajo acerca del material lítico de sitios asociados al camino del Inka en el Alto Loa describe tres piezas más, depositadas como evento fundacional de un recinto en Sba-518 (Bajada del Toro). Para Calama, se sabe de tres ejemplares en la Colección Uhle del Museo Nacional de Historia Natural (Durán et al. 2000), que podrían provenir de Chunchurí o de Chiu-Chiu. Otro antecedente proviene de Briones y Castellón (2013), en la ruta Calama-Chacance donde encontraron una pala lítica sobre un camino asociado a geoglifos.

En relación al tema agrario, la Paskana-taller TQO2 provee evidencia de consumo de maíz, que sabemos está presente en el oasis de Quillagua desde el Formativo en adelante (Agüero et al. 2006), en Chacance (P. Núñez 2002: 42) y también en la desembocadura del Loa y Cáñamo (Núñez 1976b: 84, 91). Este cultivo pudiera relacionarse con labores que empleasen las palas.

Las hachas de piedra son un verdadero enigma para los estudios tecnológicos en la región. Si bien los modelos metálicos de tiempos tardíos se han reportado en numerosas ocasiones, tanto como objeto y como representación rupestre, se las ha empleado en la discusión preferentemente como referentes del surgimiento de las economías de prestigio y el análisis de la diferenciación social. Pero, en el caso de las de piedra, que deben haber sido bastante más frecuentes que las metálicas, su historia tecnológica, distribución y asociaciones contextuales nos son completamente desconocidas, aun cuando el 


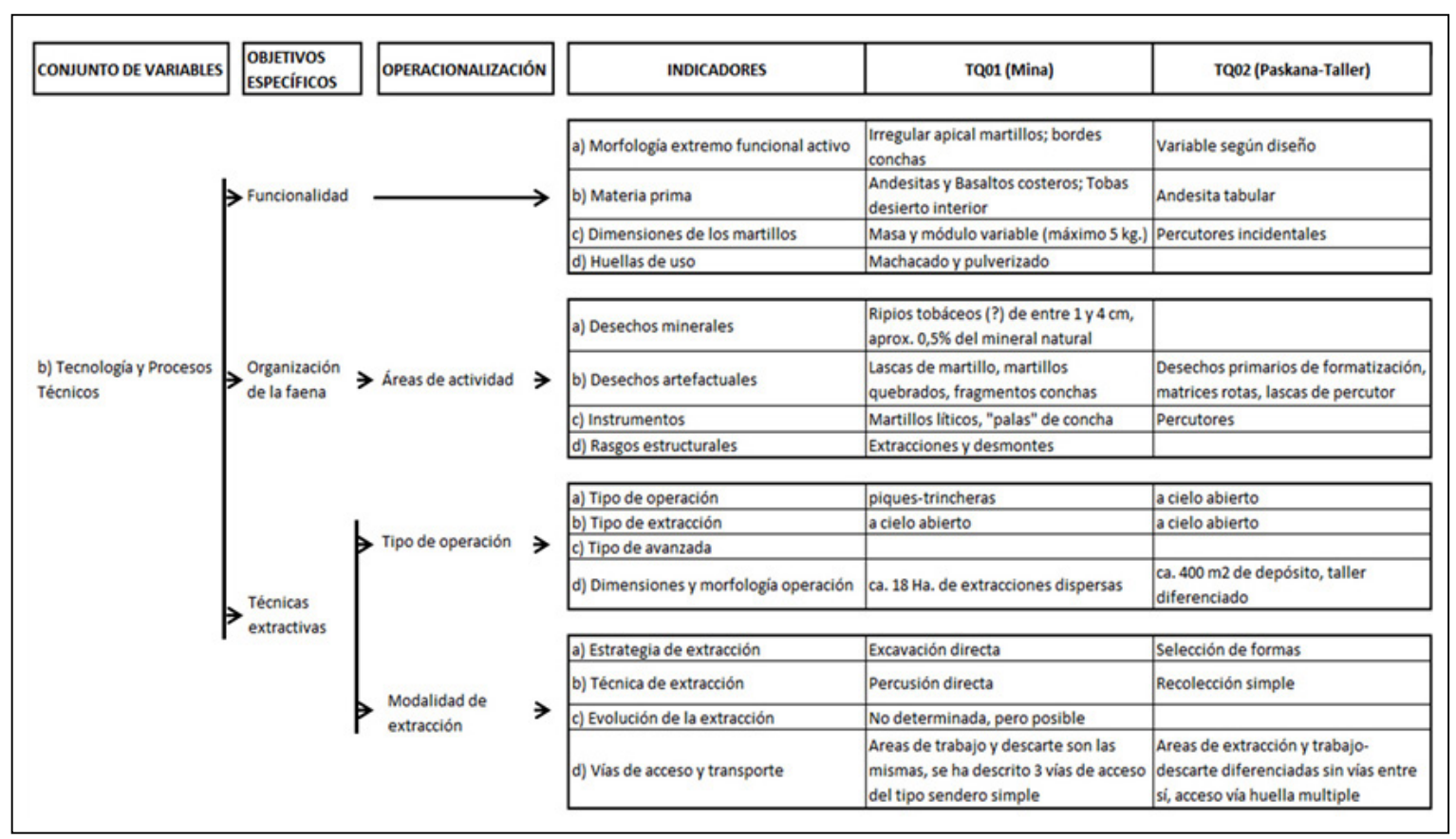

Figura 5. Comparación de los sitios extractivos de TQ dentro del esquema de Salazar y Salinas (2008), modificado.

trabajo de la madera debió ser muy importante en algunos lugares (p.e. bosques de tamarugos en Tarapacá). Éste es un ítem que aparece mencionado con muy poca frecuencia en la literatura, pero que sin embargo está presente en los inventarios de San Pedro de Atacama (cf. Tarragó 1989), aparentemente algo distintas en su diseño a las que nosotros encontramos en TQO2.

Los martillos líticos, por su parte, han sido descritos en varias ocasiones, pero sus análisis y descripciones más detallados fueron realizados por H. Salinas, para el caso de San José del Abra (Salinas 2007; Salinas y Salazar 2008 y Salinas et al. 2010). También han sido descritos por Núñez et al. (2003), para Chu-2. Por cierto, no sabemos si las piezas que tenemos en TQO2 corresponden efectivamente a martillos, al no encontrarse enmangados, con escotaduras para enmangue o sus restos, o en contexto minero, pero cuadran bien con lo descrito en el excelente trabajo sobre ergología minera de Figueroa et al. (2013), basado en parte en trabajos anteriores (p.e. Salazar y Salinas 2008), de donde extractamos una sección de modelo que resulta, concediéndonos cierta flexibilidad, aplicable para nuestras "ocupaciones extractivas" (Figura 5).

\section{$*$ Conclusiones}

Desde el punto de vista del modelaje teórico general que habíamos enunciado como relevante a nuestro trabajo (Pimentel et al. 2011), cabe notar que, aunque formulado para el Período Formativo, para el cual no obtuvimos ningún registro de "ocupación extractiva", podemos igualmente realizar un ejercicio de contraste desde los sitios descritos, si consideramos a los agentes costeros y de tierra interior como poblaciones que independientemente del tiempo, se definen diacríticamente. Si sistematizamos lo aprendido de nuestros registros sobre la base de este modelo, podemos precisar este juego de contrastes entre "ocupaciones extractivas" del Período Arcaico y del Período Tardío, como se aprecia en la tabla siguiente (Figura 6).

Salvando la gran diferencia temporal de ambos registros, se puede decir que el modelo se sostiene, con modificaciones relativas a la naturaleza del registro analizado ("ocupaciones extractivas" en lugar de "ocupaciones de tránsito"). A partir de la aplicación de este modelo, se colige que la modalidad costera trasciende en el tiempo a la más restrictiva definición realizada previamente, y al parecer se establece al menos 3 mil años antes de lo 
José F. Blanco, Itací Correa G., Carola Flores y Gonzalo Pimentel G.

\begin{tabular}{|c|c|c|c|}
\hline & Categorías & Minería Costera Arcaica (ca. 6000 AP) & Tráfico Oasis-Costa Tardío (ca. 600 AP) \\
\hline \multirow{10}{*}{ 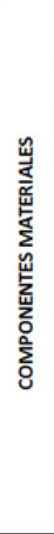 } & $\begin{array}{l}\text { Características } \\
\text { viales }\end{array}$ & $\begin{array}{l}\text { Senderos simples distintas direcciones } \\
\text { hacia la Costa, uno solo hacia el Oasis }\end{array}$ & $\begin{array}{l}\text { Senderos múltiples, sinuosos y } \\
\text { superpuestos }\end{array}$ \\
\hline & Campamentos & $\begin{array}{l}\text { Sin estructuras de alojamiento, } \\
\text { posiblemente las mismas excavaciones. }\end{array}$ & Varias estructuras de alojamiento \\
\hline & Cadena Productiva & $\begin{array}{l}\text { Escasa talla lítica; Extracción, molido, } \\
\text { limpieza y empacado de Yeso. }\end{array}$ & $\begin{array}{c}\begin{array}{c}\text { Producción de matrices de instrumentos } \\
\text { de labranza. Retoque de instrumentos en } \\
\text { silices finos. }\end{array} \\
\end{array}$ \\
\hline & $\begin{array}{l}\text { Materias primas } \\
\text { locales }\end{array}$ & Aprovisionamiento logístico de Yeso & $\begin{array}{c}\text { Aprovisionamiento inserto de Placas de } \\
\text { Andesita }\end{array}$ \\
\hline & $\begin{array}{l}\text { Materias primas } \\
\text { no locales }\end{array}$ & Rodados Litorales de Andesita y Basalto & Desechos calcedonias Oasis \\
\hline & $\begin{array}{c}\text { Tipos de } \\
\text { contenedores }\end{array}$ & Cueros (?) & Cerámica tipos QTC, QRP y PCH \\
\hline & $\begin{array}{l}\text { Recursos } \\
\text { comestibles }\end{array}$ & $\begin{array}{l}\text { Sólo productos marinos: Loco, Choro, } \\
\text { Erizo, Chitón, Fissurellas }\end{array}$ & $\begin{array}{l}\text { Sólo productos de Oasis: Algarrobo, Maíz, } \\
\text { molusco terrestre o crustáceo de río }\end{array}$ \\
\hline & Geoglifos & Ausencia & 7 motivos, 2 Paneles \\
\hline & Fecas de Camélido & Ausencia & Presencia \\
\hline & Mineral de Cobre & Presencia & Ausencia \\
\hline \multirow{5}{*}{ 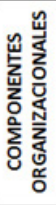 } & Infraestructura & Equipamiento minero & Señalización (Geoglifos) \\
\hline & $\begin{array}{l}\text { Escala de los } \\
\text { contingentes }\end{array}$ & Desconocido & Desconocido, pero con animales de carga \\
\hline & Alcance Espacial & ca. $20 \mathrm{~km}$ & ca. $80 \mathrm{~km}$ \\
\hline & $\begin{array}{l}\text { Intensidad del } \\
\text { tránsito }\end{array}$ & Alta intensidad y redundancia variable & Alta intensidad y redundancia \\
\hline & Objetivo principal & Aprovisionamiento logístico & Tráfico e Intercambio intersocietal \\
\hline
\end{tabular}

Figura 6. Los registros extractivos internodales de TQ versus el modelo de Pimentel et al. (2011), con modificaciones.

propuesto y con una complejidad insospechada hasta ahora. Por otra parte, se añade una nueva dimensión a la modalidad caravanera, con la implementación de un taller donde se producen herramientas para la labranza agrícola, la explotación del bosque y la minería.

Existe continuidad del sendero único arcaico al este de TQor y se conecta con el eje vial múltiple Tocopilla-Quillagua, de donde puede colegirse una mayor complejidad de la movilidad arcaica en cuanto a la interacción de agentes a distancia con el fin de sostener biológica y socioeconómicamente a los grupos. La ruta arcaica podría no ser exclusiva para aprovisionamiento logístico de minerales, sino que también implicar el tráfico e interacciones sociales. A pesar de que lo anterior no se advierte directamente en los productos de éste sitio, se imponen igualmente las siguientes preguntas: ¿Estaban los arcaicos costeros accediendo a Quillagua por esta ruta? Esto hablaría de su posible uso para fines adicionales al aprovisionamiento logístico. ¿Estaban los quillaguinos usando esta misma ruta para bajar a la costa en el arcaico, o sin caravanas en tiempos formativos y posteriores? Solo el examen de las "ocupaciones de tránsito" en la vía podrán acercarnos a estos temas.

Desde el punto de vista de la teoría general, es evidente que las bases para interpretar y explicar el uso humano de los espacios internodales, pueden ser de índole histórico-procesual como en Nielsen (2006); constructivista geográfico-diacrítico, como en Berenguer (2004); de la Teoría Social (Pimentel 2012); o de tipo Heurístico (Núñez y Nielsen 2011), entre otras muchas posibilidades. Este hecho, nos parece, no compromete la inteligibilidad del campo del conocimiento que se discute y pensamos que es esa multivocalidad teórica la que permite una mejor descripción de la complejidad de los procesos sociales andinos. Las equivalencias lógicas y conceptuales transversales a todos estos marcos teóricos, probablemente derivadas de la praxis, implican un substrato común. Si éste debe tratarse como teoría, siendo a todas vistas un paradigma, es algo que solo futuros trabajos en epistemología arqueológica podrán resolver.

Para ponderar los alcances del presente estudio, utilizamos lo observado como programáticamente importante por Berenguer (2004) en las conclusiones de su "Caravanas, Interacción y Cambio en el Desierto de Atacama", guardando las respectivas proporciones y diferencias. Esto es: 1) "complementar la perspectiva subareal con otra regional y local"; 2) "complementar la perspectiva centrada en productos, con otra focalizada en los actores y su acción de tráfico"; 3 ) "complementar la perspectiva nodal de la Movilidad Giratoria (MG) con otra internodal"; 4) 
"complementar la perspectiva socioeconómica de la MG, con otra sociopolítica" (op. cit.: 526-8). Si bien nuestro estudio no ha adscrito a la "Movilidad Giratoria" como marco teórico, todos estos objetivos programáticos fueron enfrentados, en mayor o menor medida, por nuestro análisis. Debe enfatizarse que el trabajo de Berenguer (2004), se refiere exclusivamente al caravaneo del Período Intermedio Tardío en adelante, en tanto que nosotros tomamos como base el marco teórico y metodológico de los "estudios internodales" de Nielsen (2006), ampliando expresamente su injerencia a situaciones arcaicas y sacándolo, además, de su escala espacial usual, cuestión, por lo demás, sugerida por ambos autores.

Hemos cumplido parcialmente con algunos de los objetivos programáticos comentados más arriba, y lo más importante es que se ha ofrecido una perspectiva internodal regional y local (puntos 1 y 3 ). Por otra parte, si bien nuestro trabajo no se encuentra inicialmente focalizado en el intercambio propiamente tal, ni en el análisis vial, sí se centró en los actores, al posibilitar por diseño de prospección la visibilidad del componente costero internodal, más específicamente en las actividades extractivas antes que en los productos mismos (punto 2).

Si bien la cuestión de la aplicabilidad temporal del modelo general internodal no ha sido muy estrictamente explicitada, podemos asumir con seguridad que se refiere principalmente a la movilidad con propósito de intercambio, por oposición a la movilidad residencial y extensiones logísticas propias de lógicas de cazadores recolectores, sin nodos estables. En relación a la región, solo el modelo de Movilidad Giratoria (Núñez y Dillehay 1979) comenta las situaciones arcaicas de base, empleando para ello el concepto "vectores de movilidad". Respecto de este problema, y en beneficio de una complejidad temprana (Arcaica) es que nos parece importante considerar, siguiendo a Aschero:

...las relaciones sociales de los grupos cazadores-recolectores más tempranos debieron ser altamente complejas en términos del número de interacciones requeridas -entre grupos y persona a persona- para mantener el sistema con sus interacciones a distancia. Particularmente en estos ambientes de desierto extremo, donde la disponibilidad de agua regula la vida, el acceso o control de los sectores con concentración de recursos es algo que requirió de un programa y diversas estrategias de acción alternativas (en el sen- tido de Morin 1995); un programa donde esas relaciones sociales a distancia jugaron un papel crucial. Definiría ese programa-tal como la evidencia arqueológica está mostrando-como el sostener a ultranza ese acceso a recursos variados, de ecozonas distantes, y las relaciones sociales que surgen de esas interacciones. Se trata de la construcción de ese sistema social abierto, con límites fluctuantes, dependientes de las interacciones cara a cara de agentes y grupos, donde esas relaciones sociales proveyeran un reaseguro de vida y una renovación constante del pool genético local (Aschero 2007: 158).

Por razones como las anteriormente planteadas, es que la Arqueología Internodal tiene que considerar también la interacción y movilidad Arcaica. Los aprovisionamientos de carácter logístico -típicos del Arcaico- no tienen por qué haber desaparecido con la introducción de Caravanas, sino que dicha clase de movilidad, pedestre sin animales de carga, se mantuvo, como demuestran los casos presentados por Pimentel et al. (2010 y 2011) y Pimentel (2012), precisamente para la movilidad costaLoa inferior durante el Formativo. Para poblaciones de tierras altas, no es extraño que la movilidad pedestre se mantuviera, en especial en este último período, durante el cual deben haberse dado casos de poblaciones con especialización pastoril y otras que no la tuvieron. Del mismo modo, pensamos que - más tardíamente quizás- seguramente hubo segmentos sociales de grupos sin acceso al transporte por llamas, aun cuando el grupo las poseyera. Igualmente, el propio tráfico con caravanas debe haber dejado, en ciertos momentos del año cuando éstas se realizaban, a la población restante en el nodo sin posibilidad -o con una posibilidad restringida- de acceder a este medio de transporte, siendo indispensable el aprovisionamiento pedestre y muy probable lo que Nielsen (2006) llama "tráfico incorporado", descrito como los “...intercambios y otras prácticas de apropiación de bienes insertas en contextos y programas de trabajo organizados en función de otros objetivos, independientes del traslado de objetos" (Nielsen 2006: 48). ${ }^{18}$

18 La discusión de este artículo, sobre el que basamos en parte este trabajo, presenta precisiones interesantes que vale la pena destacar con algunos extractos: “... es interesante pensar estos nodos como "capas" que se van agregando a las ya existentes en vez de desplazarlas [...] Lo que llamo "tráfico incorporado" tiene sus raíces en el Arcaico [...] la caravana parece que entrara después [... Ahora lo que tenemos que hacer es, de algún modo, mapear en el espacio cómo interactúan cada uno de estos, porque no es necesario que circulen los mismos bienes por los mismos 
Aparte de la temporalidad absoluta de los registros con que los estudios internodales deberían tratar, se impone una revisión de los temas propuestos por Nielsen (2006) para la caracterización de las "ocupaciones extractivas".

En primer término, en el marco de una antigua discusión acerca de la definición de sitio arqueológico como unidad de análisis arqueológico, el término "ocupación" había sido criticado por su pasividad (cf. Berenguer 1987; Gallardo y Cornejo 1987; Berenguer 1988), cosa que en retrospectiva parece correcta; pues si hablamos de problemas más referidos a la movilidad y el tráfico, ¿no sería más apropiado referirnos a "actividades" en lugar de "ocupaciones"?

Respecto de las ocupaciones "temporarias" y "transitorias", por otra parte, entendemos que son cosas muy distintas la caza de presas altamente móviles (p.e. guanaco, vicuña o taruca), la recolección de recursos vegetales (fijos en el espacio, estén o no disponibles acotadamente en el tiempo) y la extracción de recursos minerales (que requiere un procedimiento técnicamente complejo, difícilmente implementable por mera contingencia). La primera actividad requiere la persecución del recurso, la segunda su selección simple y la tercera su extracción. Creemos que puede procederse más parsimoniosamente -y de acuerdo a lo que sabemos de la prehistoria regional-, indicando la existencia de actividades de caza, de recolección y de extracción. Esto sería fácil de complementar con una categorización temporal relativa como la que se propone, pero más simplemente enunciada como de corto y mediano plazo, respectivamente, que depende solo de la agencia social y no estricta y únicamente de la disponibilidad ambiental de los recursos. Por lo demás, en nuestros casos de estudio (sitios TQOI y TQO2), los recursos, que son exclusivamente minerales, nos proveen de ejemplos de disponibilidad continua, donde, sin embargo, existen consideraciones temporales que hacer, de "redundancia", teniendo en cuenta la complejidad distinta de la actividad realizada, donde la recolección du-

mecanismos. Hay bienes que circulan por un mecanismo y no por otro [...] Esto de las capas que digo, se mantiene el tráfico incorporado y aparece el caravanero. Y de hecho después con el Inca aparece el tráfico formal, pero sobrevive el caravanero y sobrevive el incorporado. Y después aparece el ferrocarrily sobrevive el tráfico estatal, sobrevive el caravanero y sobrevive el incorporado [...] Entonces, este mundo de la complejidad también tiene que ver con el agregado de estos mecanismos de interacción que siguen operando simultáneamente (Nielsen en Discusión de Nielsen, Lechtman 2006: 66-7). rante el PT de matrices para herramientas de labranza es bastante más simple, de menor extensión en el tiempo y ocasional, que la extracción Arcaica de yeso, con su viaje dedicado y procesamiento y empacado, realizado recurrentemente durante varias generaciones.

Si bien hubiera sido ideal disponer en la vía estudiada de registros "sincrónicos" entre sí, para cualquier período, que permitieran acercarnos a analizar algunos aspectos económicos en un sentido más político, esto no fue así. Sin duda, deben existir registros contemporáneos en otras vías del área de estudio, considerando que en muchos casos viales conocidos esto es frecuente en lo referido a "ocupaciones de tránsito" (p.e. Pimentel et al. 2007, para un caso de tierras altas). Al menos, la investigación proveyó de datos suficientes para mostrar que el conocimiento actual de los procesos socioeconómicos prehistóricos básicos para esa discusión está aún muy incompleto.

En términos más generales, parece necesario considerar el rol de la costa como nodo de escala regional, cosa que no ha ocurrido en la bibliografía, aceptándose que, por ejemplo, nuestro tramo de costa sencillamente corresponde al área circumpuneña. Como puede notarse fácilmente, en términos de geografía humana, la población costera tiene una adaptación, base económica y tradiciones distintas a las de tierras altas, por lo cual la consideración de la costa como nodo en los análisis regionales es palmaria. Quizás sea útil a futuro, en consideración al hecho de que estas poblaciones presentan amplia movilidad latitudinal (ver p.e. Ballester y Gallardo 2011), considerar estos nodos como distintos a los interiores, por lo cual sugerimos la categoría de "nodo disperso", concepto que habrá que examinar en sus alcances y utilidad.

Agregaremos, por último, que la productividad de los estudios internodales dependerá a futuro, nos parece, de que su teoría soporte distintos niveles escalares de integración, tanto en lo espacial como en lo temporal, e incluso entre ambas dimensiones. En este sentido, la "actividad extractiva" de datos relevantes desde este tipo de registros "internodales", recién comienza.

Agradecimientos A Charles Rees, Lautaro Núñez, Mark Hubbe y a todo el equipo del proyecto FONDECYT 1090762 "Estrategias de movilidad en ejes viales preincaicos que conectaron el Loa medio y la Costa de la II región.". 
Magdalena De la Maza, Claudia Castillo y Tarek González, por su ayuda en terreno. Álex Paredes, Christian Tapia, Marco Benavente y Mauricio Vargas hicieron los levantamientos topográficos. Christina Torres-Rouff, William Pestle y Michael Deibel posibilitaron los análisis físicos y químicos. Jaime Martínez y Juan Vargas hicieron el análisis microscópico de los sedimentos de la mina. Francisco Gallardo, a través del proyecto FONDECYT 1110702, nos apoyó con dos fechas radiocarbónicas. FONDAP/CONICYT 15110009. Isabel Cartajena, Luis Cornejo, Andrés Troncoso, Lorena Sanhueza y Rodrigo Sánchez proveyeron de revisiones críticas al diseño y a la memoria que generaron este trabajo. Benjamín Ballester y Gloria Cabello realizaron importantes aportes bibliográficos. Mario Vásquez nos envió gentilmente su tesis. Los revisores anónimos hicieron también relevantes aportes críticos.

\section{* Referencias citadas}

AGÜERO, C., M. URIBE, P. AYALA, B. CASES y C. CARRASCO. 2001. Ceremonialismo del período Formativo en Quillagua, Norte Grande de Chile. Boletín de la Sociedad Chilena de Arqueología 32: 24-34.

AGÜERO, C., P. AYAlA, M. URIBE, C. CARRASCO y B. CASES. 2006. El período formativo desde Quillagua, Loa Inferior (norte de Chile). En Esferas de interacción prehistóricas y fronteras nacionales modernas: los Andes Sur Centrales. H. Lechtman (Ed.), pp. 73-120. Instituto de Estudios Peruanos-Institute of Andean Resarch, Lima.

ANDREFSKY, W. 2000. Lithics. Macroscopic approaches to analysis. Cambridge Manuals in Archaeology. Cambridge University Press. New York, NY.

ARCE, I. 1997 [1930]. Narraciones históricas de Antofagasta. Lama Industrial, Antofagasta.

ARRIAZA, B. y V. STANDEN. 2008. Bioarqueología. Historia Biocultural de los antiguos pobladores del extremo norte de Chile. Editorial Universitaria, Santiago.

ARRIAZA, B., K. REINHARD, K. ARAÚJO, N. ORELLANA y V. STANDEN. 2010. Possible influence of the ENSO phenomenon on the pathoecology of Diphyllobothriasis and anisakiasis in ancient Chinchorro population. Memorias do Instituto Oswaldo Cruz 105(1): 66-72.

ASCHERO, C. 1975 Ms. Ensayo para una clasificación morfológica de artefactos líticos aplicada a estudios tipológicos comparativos. Informe al CONICET, Buenos Aires.

ASCHERO, C. 2007. Íconos, huancas y complejidad en la Puna sur argentina. En Procesos Sociales Prehispánicos en el Sur Andino: La vivienda, la comunidad y el territorio. Colección Historia Social Precolombina, vol. 2, A. Nielsen, M. Rivolta, V. Seldes, M. Vásquez y P. Mercolli (Eds.), pp. 259-290. Editorial Brujas, Córdoba.
ÁVALOS, J. 1998. Modos de uso de implementos agrícolas de la Quebrada de Humahuaca y Puna a través del análisis de huellas de desgaste. En Los desarrollos locales y sus territorios: Arqueología del NOA y Sur de Bolivia, B. Cremonte (Comp.), pp. 285-303. Universidad Nacional de Jujuy, Jujuy.

BALLESTER, B. y F. GALLARDO. 2011. Prehistoric and historic networks on the Atacama Desert coast (northern Chile). Antiquity 85: 875-889.

BATE, L. 1971. Material lítico: Metodología de clasificación. Noticiario Mensual del Museo Nacional de Historia Natural 181-182: 3-24.

BERENGUER, J. 1987. Problemas con la definición de sitio arqueológico. En Arqueología y Ciencia: Segundas Jornadas, F. Gallardo, L. Suárez y L. Cornejo (Eds.) pp. 61-80. Imprenta Museo Nacional de Historia Natural, Santiago.

BERENGUER, J. 1988. Comentario a "Definiendo el sitio Arqueológico: Metodología en acción" de Francisco Gallardo y Luis Cornejo. Boletín de la Sociedad Chilena de Arqueología 8: 9-11.

BERENGUER, J. 1994. Asentamientos, caravaneo y tráfico de larga distancia en el norte de Chile: El caso de Santa Bárbara. En De Costa a Selva: Intercambio y Producción en los Andes Centro-Sur, M. Albeck (Ed.), pp. 17-49. Instituto Interdisciplinario de Tilcara, Universidad de Buenos Aires, Buenos Aires.

BERENGUER, J. 2004. Tráfico de caravanas, interacción interregional y cambio en el Desierto de Atacama. Ediciones Sirawi, Santiago, Chile.

BERENGUER, J. y G. PIMENTEL. 2010. Presentación de simposio "Arqueología de los Espacios Vacíos: una aproximación internodal a las relaciones societales". En Actas del XVII Congreso Nacional de Arqueología Chilena, tomo 2, pp. 1305-1308. Universidad Austral de Chile, Valdivia. 
José F. Blanco, Itací Correa G., Carola Flores y Gonzalo Pimentel G.

BHAGAVANTAM, S. 1938. Interpretation of Raman Spectra in Crystals: Anhydrite and Gypsum. Proceedings of the Indian Academy of Science, Section A: 345-348.

BITTMANN, B. y J. MUNIZAGA. 1984. Evolución en poblaciones precolombinas de la costa Norte de Chile. Chungara 13: 129-142.

BLANCO, J. 2013. La extracción prehispánica de minerales en el internodo Quillagua-Costa, Desierto de Atacama. Memoria para optar al título de Arqueólogo. Universidad de Chile, Santiago.

BLANCO, J., M. DE LA MAZA y CH. REES. 2010. Cazadores recolectores costeros y el aprovisionamiento de recursos líticos. Perspectivas interpretativas de los eventos de talla en el desierto absoluto. Werkén 13: 45-68.

BONAVIA, D., L. JOHNSON, E. REITZ, E. WING y G. WEIR. 1993. Un sitio precerámico de Huarmey (PV35-6) antes de la introducción del Maíz. Bulletin de l'Institut Français d'Etudes Andines 22(2): 409-442.

BRIONES, L. y C. CASTELLÓN. 2013. Catastro de Geoglifos. Provincia de Tocopilla, Región de Antofagasta, Chile. Consejo Nacional de la Cultura y las Artes, Valparaíso.

BROWMAN, D. 2004. Tierras comestibles de la Cuenca del Titicaca: Geofagia en la prehistoria boliviana. Estudios Atacameños 28: 133-141.

BROWMAN, D. y J. GUNDERSEN. 1993. Altiplano Comestible Earths: Prehistoric and Historic Geophagy of Highland Peru and Bolivia. Geoarchaeology: An International Journal (8)5: 413-425.

CASES, B., CH. REES, G. PIMENTEL, R. LABARCA y D. LEIVA. 2008. Sugerencias desde un contexto funerario en un "espacio vacío" del Desierto de Atacama. Boletín del Museo Chileno de Arte precolombino 13(1): 51-70.

CERVELLINO, M. y F. TÉLLEZ. 1980. Emergencia y desarrollo en una aldea prehispánica de Quillagua-Antofagasta. Contribución Arqueológica 1 (Copayapu). Museo regional de Atacama, Copiapó.

CLAASSEN, C. 2000. Quantifying shell: comments on Mason, Peterson, and Tiffany. American Antiquity 65 (2): 415-418.

CONTRERAS, R., J. CRUZ, A. LLAGOSTERA, H. GARCÉS, P. NÚÑEZ, O. RODRÍGUEZ, H. GÁRATE y G. BECERRA. 2007. Los Bronces-1. Un asentamiento de 5.500 años en la costa de Taltal. Museo Augusto Capdeville, Taltal.

CORREA, I. y M. GARCÍA. 2014. Cerámica y contextos de tránsito en la ruta Calama-Quillagua, vía Chug-chug, Desierto de Atacama, norte de Chile. Chungara (Arica) 46(1): 25-50.
DORN, R. 2009. The Rock Varnish Revolution: New Insights from Microlaminations and the Contributions of Tanzhuo Liu. Geography Compass 3: 1-20.

DURÁN, E., M. KANSINGER y N. ACEVEDO. 2000. Colección Max Uhle: Expedición a Calama 1912. Publicación Ocasional Museo Nacional de Historia Natural núm. 56. Museo Nacional de Historia Natural, Santiago.

FIGUEROA, V., D. SALAZAR, H. SALINAS, P. NÚÑEZ-REGUEIRO y G. MANRÍQUEZ. 2013. Pre-hispanic mining ergology of northern Chile: an archaeological perspective. Chungara (Arica) 45(1): 61-81.

FOCACCI, G. 1990. Excavaciones arqueológicas en el cementerio AZ-6 Valle de Azapa. Primera Parte. Fase Cabuza. Chungara 24/25: 69-123.

FOUANT, M., M. ALLISON, F. GERSZTEN y G. FOCACCI. 1982. Parásitos intestinales entre los indígenas precolombinos. Chungara 9: 285-299.

GALARCE, P. y G. SANTANDER. 2013. Contextos líticos de asentamientos arcaicos en la costa de Taltal (II Región, Chile). Estudios Atacameños 46: 5-26.

GALLARDO, F., B. BALLESTER Y N. FUENZALIDA (Eds.). 2015 Ms. Monumentos funerarios de la costa del Desierto de Atacama. Contribuciones al intercambio de bienes e información entre cazadores-recolectores marinos, norte de Chile. Proyecto FONDECYT 1110702. Centro Interdisciplinario de Estudios Interculturales e Indígenas.

GALLARDO, F., L. CORNEJO, R. SÁNCHEZ, B. CASES, A. ROMÁN y A. DEZA. 1993. Arqueología en el valle de Quillagua, río Loa, Norte de Chile. Gaceta Arqueológica Andina 23: 125-138.

GALLARDO, F. y L. CORNEJO. 1987. Definiendo el sitio arqueológico: metodología en acción. Boletín de la Sociedad Chilena de Arqueología 7: 6-11.

GEORGE-NASCIMENTO, M. y J. CARVAJAL. 1981. Helmintos parásitos del lobo marino común Otaria flavescens en el Golfo de Arauco, Chile. Boletín Chileno de Parasitología 36: 72-73.

GLASSOW, M. 200o. Weighing vs. Counting shellfish remains: a comment on Mason, Patterson, and Tiffany. American Antiquity 65(2): 407-414

GONZÁLEZ, C. y K. WESTFALL. 2010. Cementerio Regimiento Chorrillos de Calama: testimonios funerarios formativos en el Loa Medio, Región de Antofagasta. En Actas del XVII Congreso Nacional de Arqueología Chilena, tomo 2, pp. 95-105. Universidad Austral de Chile, Valdivia. 
GUSINDE, M. 1982. Los Indios de la Tierra del Fuego. Tomo I, vol. I: Los Selknam. (Traducción de Oscar Aguilera F.). Centro Argentino de Etnología Americana, Buenos Aires.

GUZMÁN, N., SH. SAÁy L. ORTLIEB. 1998. Catálogo descriptivo de los moluscos litorales (Gastropoda y Pelecypoda) de la zona de Antofagasta, $23^{\circ} \mathrm{S}$ (Chile). Estudios Oceanológicos 17: 17-86.

HELDAL, T., E. BLOXAM, P. DEGRYSE, P. STOREMYR y A. KELANY. 2009. Gypsum quarries in the northern Faiyum quarry landscape, Egypt: a geo-archaeological case study. En QuarryScapes: ancient stone quarry landscapes in the Eastern Mediterranean, N. Abu-Jaber, E. Bloxam, P. Degryse y T. Heldal (Eds.), pp. 51-66. Geological Survey of Norway Special publication 12.

IÑÍGUEZ, A., K. REINHARD, A. ARAÚJO, L. FERREIRA y C. VICENTE. 2003. Enterobius vermicularis: Ancient DNA from North and South American Human Coprolites. Memorias do Instituto Oswaldo Cruz 98 (suppl. I): 67-69.

KENNEDY M. y P. WATSON. 1997. The Chronology of Early Agriculture and Intensive Mineral Mining in the Salts Cave and Mammoth Cave Region, Mammoth Cave National Park, Kentucky. Journal of Cave and Karst Studies 59(1): 5-9.

KNUDSON, K., W. PESTlE, C. TORRES-ROUFF y G. PIMENTEL. 2010. Assessing the life history of an andean traveller through biogeochemistry: stable and radiogenic isotope analyses of archaeological human remains from Northern Chile. International Journal of Osteoarchaeology 22 (4): 435-451.

LATCHAM, R. 1933. Notas preliminares de un viaje arqueológico a la localidad de Quillagua. Revista Chilena de Historia y Geografía 34: 130-138.

LATCHAM, R. 1938. Arqueología de la región atacameña. Prensas de la Universidad de Chile.

LECHTMAN, H. (Ed.). 2006. Esferas de interacción prehispánicas y fronteras nacionales modernas: los Andes sur centrales. Instituto de Estudios Peruanos-Institute of Andean Resarch, Lima.

LLAGOSTERA, A. 1990. La navegación prehispánica en el norte de Chile: Bioindicadores e inferencias teóricas. Chungara 24/25:37-51.

LIU, T. y W. S. BROECKER. 2007. Holocene rock varnish microstratigraphy and its chronometric application in the drylands of western USA. Geomorphology 84: 1-21.

LUCERO M. 2004. Evaluación del uso de artefactos de concha en el poblamiento inicial del semiárido de Chile. Memoria para optar al título de Arqueóloga. Universidad de Chile, Santiago.
MARINCOVICH, L. 1973. Intertidal mollusks of Iquique, Chile. Los Angeles County Natural History Museum Science Bulletin 16: 1-49.

MASON R., M. PETERSON y J. TIFFANY. 1998. Weighing vs. Counting: measurement reliability and the California school of midden analysis. American Antiquity 63(2):303-324.

MASON R., M. PETERSON y J. TIFFANY. 200o. Weighing vs. Counting: a response to Glassow and Claassen. American Antiquity 65(4): 757-761.

MENA, F. 1984. Patrones de movilidad en el Arcaico Tardío: II Región. Estudios Atacameños 7: 25-35.

MÉNDEZ, C. 2007. Tecnología lítica en el Camino Inca del Alto Loa, norte de Chile. Estudios Atacameños, Arqueología y Antropología Surandinas 33: 39-57.

MÉNDEZ-QUIRÓS, P. y M. URIBE. 2010. Análisis estratigráfico y cronología del complejo cultural Pica-Tarapacá (950-1450 d.C.). En Actas del XVII Congreso Nacional de Arqueología Chilena, tomo 2, pp. 47-57. Universidad Austral de Chile, Valdivia.

MONTENEGRO, N. 1982. Sitio Punta Guasilla 1, un Aporte a la Arqueología del Norte Desértico de Chile. Memoria para optar al título de Arqueólogo. Universidad del Norte-Chile, Antofagasta.

NARANJO, J. y R. PASKOFF. 1982. Estratigrafía de las unidades sedimentarias cenozoicas de la cuenca del río Loa en la Pampa del Tamarugal, Región de Antofagasta, Chile. Revista Geológica de Chile 15: 49-57.

NIELSEN, A. 2006. Estudios internodales e interacción interregional en los Andes circumpuneños. En Esferas de Interacción prehistóricas y fronteras nacionales modernas: los Andes sur centrales, $\mathrm{H}$. Lechtmann (Ed.), pp. 29-62. Instituto de Estudios PeruanosInstitute of Andean Resarch, Lima.

NIELSEN, A. 2015. Behavior and Practice in Archaeology: A Realist View. Chapter 13. En Explorations in Behavioral Archaeology, W. H. Walker y J. Skibo (Eds.), pp. 170-186. The University of Utah Press, Salt Lake City, UT.

NIELSEN, A., P. MERCOLLI y N. NASIF. 2010. Ocupaciones temporarias y explotación faunística en la región lacustre altoandina. En Actas del XVII Congreso Nacional de Arqueología Chilena, tomo 2, pp. 1365-1378. Universidad Austral de Chile, Valdivia.

NÚÑEZ, L. 1972. Secuencia y cambio en los asentamientos humanos de la desembocadura del río Loa, en el norte de Chile. Boletín de la Universidad de Chile 112: 3-25. 
José F. Blanco, Itací Correa G., Carola Flores y Gonzalo Pimentel G.

NÚÑEZ, L. 1975. Dinámica de grupos precerámicos en el perfil de la costa y altiplano. Norte de Chile. Estudios Atacameños 3: 59-74.

NÚÑEZ, L. 1976a. Geoglifos y tráfico de caravanas en el desierto chileno. En Volumen de Homenaje al R.P. Gustavo Le Paige. L. Núñez (Ed.), pp. 147-201. Universidad del Norte-Chile, Antofagasta.

NÚÑEZ, L. 1976b. Registro regional de fechas radiocarbónicas del Norte de Chile. Estudios Atacameños 9: 14-123.

NÚÑEZ, L. 1984. Secuencia de asentamientos prehistóricos del área de Taltal. Futuro 8: 28-76.

NÚÑEZ, L. y J. VARELA. 1967-1968. Sobre los recursos de agua y el poblamiento prehispánico de la costa del Norte Grande de Chile. Estudios Arqueológicos 3-4: 7-42.

NÚÑEZ, L. y T. DILLEHAY. 1979. Movilidad giratoria, armonía social $y$ desarrollo en los Andes Meridionales: Patrones de tráfico e interacción económica (Ensayo). Universidad del Norte-Chile, Antofagasta.

NÚÑEZ, L., C. AGÜERO, B. CASES y P. DE SOUZA. 2003. El campamento minero Chuquicamata-2 y la explotación cuprífera prehispánica en el Desierto de Atacama. Estudios Atacameños 25: 7-34.

NÚÑEZ, L. y A. NIELSEN. 2011. Caminante, sí hay caminos: Reflexiones sobre el tráfico sur andino. En En Ruta. Arqueología, Historia y Etnografía del Trafico Sur Andino. L. Núñez y A. Nielsen (Eds.), pp. 11-41. Grupo Editor Encuentro, Córdoba.

NÚÑEZ, P. 1974. Nota sobre la aldea preagrícola Caleta Huelén 42, Desembocadura del Río Loa, Norte de Chile. Documentos de trabajo 5: 27-43.

NÚÑEZ, P. 2002. Chacance, los primeros pampinos. Impresión Ercilla.

ODELL, G. 2003. Lithic Analysis. Manuals in Archaeological Method, Theory, and Technique. Springer, New York.

OLMOS, O. y J. SANHUEZA. 1984. El precerámico en la costa sur de Iquique. Chungara 13: 143-154.

ORTLIEB, L. 1995. Paleoclimas cuaternarios en el Norte Grande de Chile. En Cambios cuaternarios en América del Sur, Argollo y Mourguiart (Eds.), pp. 225-246.

PAUKETAT, T. 2001. Practice and History in Archaeology: an Emerging Paradigm. Anthropological Theory 1(1): 73-98.

PERALTA, P., C. GONZÁLEZ, C. WESTFALLy G. SANTANDER. 2010. Primeras aproximaciones sobre la arqueología de Pampa Austral: Explotación y tecnología lítica al interior de la Región de
Atacama (Chile). En Actas del XVII Congreso Nacional de Arqueología Chilena, tomo 2, pp. 297-306. Universidad Austral de Chile, Valdivia.

PÉREZ, S. 2010a. Estrategias tecnológicas conservadas en contextos agropastoriles tempranos de la puna meridional argentina. Chungara, Revista de Antropología Chilena 42 (2): 405-418.

PÉREZ, S. 2o1ob. Variabilidad en la producción de palas y/o azadas líticas de la puna argentina. Estudios Atacameños, Arqueología y Antropología Surandinas 40: 5-22.

PIMENTEL, G. 2011. Geoglifos e imaginarios sociales en el Desierto de Atacama (Región de Antofagasta, Chile). En Temporalidad, Interacción y Dinamismo Cultural. La búsqueda del hombre. Homenaje al Profesor Lautaro Núñez Atencio, A. Hubert, J. A. González y M. Pereira (Eds.), pp. 163-200. Universidad Católica del Norte.

PIMENTEL, G. 2012. Redes viales prehispánicas en el desierto de Atacama. Viajeros, Movilidad e Intercambio. Tesis para optar al grado de Doctor en Antropología, mención Arqueología. Universidad Católica del Norte - Universidad de Tarapacá.

PIMENTEL, G., I. MONTT, J. BLANCO y Á. REYES. 2007. Infraestructura y prácticas de movilidad en una ruta que conectó el Altiplano Boliviano con San Pedro de Atacama (II Región, Chile). En Procesos Sociales Prehispánicos en el Sur Andino: La vivienda, la comunidad y el territorio. Colección Historia Social Precolombina, vol. 2, A. Nielsen, M. Rivolta, V. Seldes, M. Vásquez y P. Mercolli (Eds.), pp. 351-382. Editorial Brujas, Córdoba.

PIMENTEL, G., CH. REES, P. DE SOUZA y L. ARANCIBIA. 2011. Viajeros costeros y caravaneros. Dos estrategias de movilidad en el período Formativo del Desierto de Atacama, Chile. En En Ruta. Arqueología, Historia y Etnografía del Trafico Sur Andino, L. Núñez y A. Nielsen (Eds.), pp. 43-81. Grupo Editor Encuentro, Córdoba.

POLLARD, G. 1970. The Cultural Ecology of Ceramic Stage Settlement in the Atacama Desert. Ph.D. Dissertation, Department of Anthropology, Columbia University, New York.

PUEYO, J., G. CHONG y M. VEGA. 1998. Mineralogía y evolución de las salmueras madres en el yacimiento de nitratos Pedro de Valdivia, Antofagasta, Chile. Revista Geológica de Chile 25(1): 3-15.

RICE, P. 1987. Pottery Analysis: A Sourcebook. University of Chicago Press, Chicago.

ROMÁN GASTALDI, M. 2007. Tecnología y sociedad: Biografía e Historia Social de las Palas del Oasis de Tebenquiche Chico, Puna de Atacama, Primer Milenio d.C. BAR International Series. 
SALAZAR, D. y H. SALINAS. 2008. Tradición y transformaciones en la organización de los sistemas de producción mineros en el norte de Chile prehispánico: San José del Abra, Siglos I al XVI d.C. En Mina y metalurgia en los Andes del Sur, desde la época prehispánica hasta el siglo XVII, P. Cruz y J. Vacher (Eds.), pp. 163-200. Institut de Recherche pour le Développement-Instituto Francés de Estudios Andinos, Lima.

SALAZAR, S., y F. VILCHES. 2014. La arqueología de la minería en el Centro-Sur Andino: balance y perspectivas. Estudios Atacameños, Arqueología y Antropología Surandinas 48: 5-21.

SALAZAR, D., V. FIGUEROA, B. MILLE, D. MORATA y H. SALINAS. 2010a. Metalurgia prehispánica en las sociedades costeras del norte de Chile (Quebrada Mamilla, Tocopilla). Estudios Atacameños, Arqueología y Antropología Surandinas 40: 23-42.

SALAZAR, D., V. CASTRO, J. MICHELOW, H. SALINAS, V. FIGUEROA y B. MILLE. 2olob. Minería y metalurgia en la costa arreica de la región de Antofagasta, Norte de Chile. Boletín del Museo Chileno de Arte Precolombino 15 (1): 9-23.

SALAZAR, D., D. JACKSON, J. GUENDON, H. SALINAS, D. MORATA, V. FIGUEROA, G. MANRÍQUEZ y V. CASTRO. 2011. Early Evidence ( $c a .12,000 \mathrm{BP}$ ) for Iron Oxide Mining on the Pacific Coast of South America. Current Anthropology 52(3): 463-475.

SALAZAR, D., H. SALINAS, J. L. GUENDON, D. JACKSON y V. FIGUEROA. 2013. Hunter-Gatherer-Fisher mining during the Archaic period in Coastal Northern Chile. Chapter 7. En Mining and Quarrying in the Ancient Andes, Interdisciplinary Contributions to Archaeology. N. Tripcevich y K. Vaughn (Eds.), pp. 137-156. Springer, New York.

SALINAS, H. 2007. Estudios acerca de la organización de la tecnología minera prehispánica en el Loa Superior, norte de Chile. Memoria para optar al título de Arqueólogo. Facultad de Ciencias Sociales, Universidad de Chile, Santiago.

SALINAS, H. y D. SALAZAR 2008. Cadenas operativas y sistemas de explotación minera prehispánica. En Puentes hacia el pasado: Reflexiones teóricas en arqueología, D. Jackson, D. Salazar y A. Troncoso (Eds.), pp. 73-91. Monografías de la Sociedad Chilena de Arqueología 1, Santiago.

SALINAS, H., D. SALAZAR, D. ÓRDENES y J. PARRA. 2010. Organización tecnológica y sistemas de explotación minera prehispánica. En Actas del XVII Congreso Nacional de Arqueología Chilena, tomo 2, pp. 1099-1109. Universidad Austral de Chile, Valdivia.

SCHAEDEL, R. 1957. Informe general sobre la expedición a la zona comprendida entre Arica y La Serena. En Arqueología Chilena. Con- tribuciones al estudio de la región comprendida entre Aricay La Serena, pp. 5-41. Centro de Estudios Antropológicos, Universidad de Chile.

SHEPARD, A. 1985 [1956]. Ceramics for the Archaeologist. Carnegie Institute of Washington, Washington, D.C.

SINCLAIRE, C., M. URIBE, P. AYALA y J. GONZÁLEZ. 1998. La alfarería del Período Formativo en la región del Loa Superior: sistematización y tipología. En Actas del XIV Congreso Nacional de Arqueología Chilena, vol. 2. pp. 285-314. Contribución Arqueológica 5, Copiapó.

SPAHNI, J. C. 1964. Fouilles archéologiques dans les deux cimetières indigènes de Turi, Désert D'Atacama (Chili). Bulletin Société Suisse des Americanistes 53: 2-22.

STOERTZ, G. y G. ERICKSEN. 1974. Geology of Salars in Northern Chile. Geological survey professional paper 811. United States Government printing office.

TARRAGÓ, M. 1989. Contribución al conocimiento arqueológico de las poblaciones de los oasis de San Pedro de Atacama en relación con los otros pueblos puneños, en especial al sector septentrional del valle Calchaquí. Tesis doctoral. Universidad Nacional de Rosario, Rosario.

TORRES-ROUFF, C., W. PESTLE y F. GALLARDO. 2012. Eating fish in the driest desert in the world: osteological and biogeochemical analyses of human skeletal remains from the San Salvador cemetery, North Chile. Latin American Antiquity 23 (1): 51-69.

URIBE, M. 2004. Alfarería, arqueología y metodología. Aporte y proyecciones de los estudios cerámicos del Norte Grande de Chile. Tesis para obtener el grado de Magíster en Arqueología. Universidad de Chile, Santiago.

URIBE, M. 2006. Sobre cerámica, su origen y complejidad social en los Andes del Desierto de Atacama, Norte de Chile. En Esferas de Interacción prehistóricas y fronteras nacionales modernas: los Andes sur centrales, H. Lechtmann (Ed.), pp. 449-493. Instituto de Estudios Peruanos-Institute of Andean Research, Lima.

URIBE, M. y P. AYALA. 2004. La alfarería de Quillagua en el contexto formativo del Norte Grande de Chile (1000 a.C. - 500 d.C.). Chungará, Revista de Antropología Chilena. Vol. Esp. T. II: 585-598.

URIBE, M. y C. CARRASCO. 1999. Tiestos y piedras talladas de Caspana: La producción alfarera y lítica en el Período Intermedio Tardío del Loa Superior. Estudios Atacameños 18: 55-71.

URIBE, M. y E. VIDAL. 2012. Sobre la secuencia cerámica del Período Formativo de Tarapacá (900 a.C. - 900 d.C.): Estudios en Pircas, Caserones, Guatacondo y Ramaditas, Norte de Chile. Chungara 44(2): 209-245. 
URIBE, M., L. SANHUEZA y F. BAHAMONDES. 2007. La Cerámica prehispánica Tardía de Tarapacá, sus valles interiores y Costa desértica, norte de Chile (ca. 900-1.450 D.C.): Una propuesta tipológica y cronológica. Chungara (Arica) 39 (2):143-170.

URREJOLA, C. y M. ORELLANA. 20oo. Explotación de recursos líticos de la zona desértica al interior de Taltal. En Libro de Resúmenes. XV Congreso Nacional de Arqueología Chilena, pp. 86-87.

VÁSQUEZ, M. 2005. Análisis de materiales Líticos en el Pucará de Turi, cadenas operativas y actividades líticas. Memoria para optar al título de Arqueólogo. Departamento de Antropología, Facultad de Ciencias Sociales, Universidad de Chile, Santiago.
WEIR, G. y D. BONAVIA. 1985. Coprolitos y dieta del precerámico tardío de la Costa Peruana. Bulletin de l'Institut Français d'Etudes Andines 15(1-2): 85-140.

WOODS HOLE OCEANOGRAPHIC INSTITUTE (WHOI). 1952. The history of the prevention of fouling. Chapter 11. En Marine fouling and its prevention, pp. 211-223. U.S. Naval Institute, Annapolis, Maryland.

YOUNG, S., P. SHERMAN, J. LUCKS y G. PELTO. 2011. Why on earth?: Evaluating hypotheses about the physiological functions of human Geophagy. The quarterly review of Biology 86(2): 97-120. 